\title{
Complement as driver of systemic inflammation and organ failure in trauma, burn, and sepsis
}

\author{
Marco Mannes $^{1} \cdot$ Christoph Q. Schmidt ${ }^{2} \cdot$ Bo Nilsson $^{3} \cdot$ Kristina N. Ekdahl $^{3,4} \cdot$ Markus Huber-Lang $^{1}$ (D)
}

Received: 8 March 2021 / Accepted: 23 May 2021 / Published online: 30 June 2021

(C) The Author(s) 2021

\begin{abstract}
Complement is one of the most ancient defense systems. It gets strongly activated immediately after acute injuries like trauma, burn, or sepsis and helps to initiate regeneration. However, uncontrolled complement activation contributes to disease progression instead of supporting healing. Such effects are perceptible not only at the site of injury but also systemically, leading to systemic activation of other intravascular cascade systems eventually causing dysfunction of several vital organs. Understanding the complement pathomechanism and its interplay with other systems is a strict requirement for exploring novel therapeutic intervention routes. Ex vivo models exploring the cross-talk with other systems are rather limited, which complicates the determination of the exact pathophysiological roles that complement has in trauma, burn, and sepsis. Literature reporting on these three conditions is often controversial regarding the importance, distribution, and temporal occurrence of complement activation products further hampering the deduction of defined pathophysiological pathways driven by complement. Nevertheless, many in vitro experiments and animal models have shown beneficial effects of complement inhibition at different levels of the cascade. In the future, not only inhibition but also a complement reconstitution therapy should be considered in prospective studies to expedite how meaningful complement-targeted interventions need to be tailored to prevent complement augmented multi-organ failure after trauma, burn, and sepsis.

This review summarizes clinically relevant studies investigating the role of complement in the acute diseases trauma, burn, and sepsis with important implications for clinical translation.
\end{abstract}

Keywords Trauma $\cdot$ Burn $\cdot$ Sepsis $\cdot$ Complement activation $\cdot$ Thromboinflammation $\cdot$ Systemic inflammation $\cdot$ Clinical translation

This article is a contribution to the Special issue on: Complement \& Disease: Out of the Shadow into the Spotlight - Guest Editors: Daniel Ricklin \& Richard B. Pouw

Markus Huber-Lang

markus.huber-lang@uniklinik-ulm.de

1 Institute of Clinical and Experimental Trauma-Immunology, University Hospital of Ulm, Helmholtzstr. 8/2, 89081 Ulm, Germany

2 Institute of Pharmacology of Natural Products and Clinical Pharmacology, Ulm University, Ulm, Germany

3 Department of Immunology, Genetics and Pathology (IGP), Rudbeck Laboratory C5:3, Uppsala University, Uppsala, Sweden

4 Linnaeus Center of Biomaterials Chemistry, Linnaeus University, Kalmar, Sweden

\section{Introduction}

Medical care has been extraordinarily improved for a variety of diseases in the last decades. This is because of the increasing knowledge on the pathophysiology but also due to growing awareness about risk factors fostering the development of preventive arrangements that reduce the disease burden. However, for acute diseases including trauma and burn which can hit an individual independently of gender and age, preventive medical intervention is not possible. This is illustrated by the fact that trauma is a major cause for morbidity and mortality within the younger population [1]. Globally, almost 5 million people died as a consequence of traumatic injuries in 2013 [2], and approximately 120,000 deaths were registered to be associated with heat and hot substance injuries in 2017 [3]. If initial injuries are not fatal, patients have to deal with a complex immune reaction characterized by a strong activation 
of the complement system and a massive release of proinflammatory molecules that aim to aid healing but instead can turn into induction of life-threatening inflammation [4]. Disruption of the physical skin barrier caused by trauma or burn facilitates infiltration of bacteria, thus increasing the susceptibility to sepsis. Especially burn injuries are described to be associated with a very high risk of sepsis [5]. Since the complement system is a major disease driver in the acute phase after injury, it is of paramount importance to understand its specific role in traumatic scenarios and integrate those into the body's overall immune surveillance.

This review aims to summarize the role of the complement system in the settings of trauma, burn, and sepsis with a focus on the clinical and therapeutical aspects.

\section{As old as trauma, burn, and sepsis: the complement system}

The complement system functions as an alarm system and accounts for a substantial part of the innate immunity fighting at the sharp end against invaders. However, having initially believed to be just a heat-labile factor that "complements" the action of antibodies by forming complexes with antimicrobial properties [6], in the last decades, the complement system was found to participate in a wide range of physiological and pathophysiological conditions. Inflammatory disturbance, organ development, thrombotic disorders, and tissue regeneration have been established as processes with crucial contributions by different complement activation products [7-10]. Uncontrolled complement activation and imbalanced regulation caused by injuries like trauma, burn, and sepsis can deteriorate the outcome of patients.

Complement is classically a "three-arm" branched system acting in a cascade-like fashion. It consists of more than 50 proteins, many of them being zymogens which become activated upon proteolytic cleavage. The activation of the classical pathway (CP) is based on the recognition of IgM or multimeric (ideally hexameric) IgG antibody patterns by $\mathrm{C} 1 \mathrm{q}$ which entails a conformational change in $\mathrm{C} 1 \mathrm{q}$ eventually leading to the activation of its associated proteases $\mathrm{C} 1 \mathrm{r}$ and $\mathrm{C} 1 \mathrm{~s}$. The latter of which can cleave $\mathrm{C} 4$ and $\mathrm{C} 2$, together forming the classical pathway $\mathrm{C} 3$ convertase $\mathrm{C} 4 \mathrm{~b} 2 \mathrm{a}$. The same convertase, albeit by the action by the MASP-1 and -2 proteases, also emanates from the lectin pathway (LP) when pattern recognition molecules such as mannose-binding lectin, ficolins, and collectins perceive microbe-associated molecular patterns (MAMPs). In addition, many of these recognition molecules (including $\mathrm{C} 1 \mathrm{q}$ ) also identify various damageassociated molecular patterns (DAMPs), i.e., altered selfstructures which are released by or exposed on necrotic and/ or apoptotic cells and bodies, thereby initiating complement activation.
While the classical and lectin pathways are turned on specifically, the alternative pathway (AP) is active all the time. At a low level, C3 activates continuously and indiscriminately assembling early AP convertases that cleave $\mathrm{C} 3$ into $\mathrm{C} 3 \mathrm{~b}$ [11]. All pathways converge at the proteolytic cleavage of the central protein $\mathrm{C} 3$ generating the anaphylatoxin $\mathrm{C} 3 \mathrm{a}$ and the opsonin $\mathrm{C} 3 \mathrm{~b}$. The latter exposes a hidden thioester moiety allowing the covalent attachment especially to free hydroxyl or amino groups. Released anaphylatoxins attract immune cells to the site of infection. By binding to its receptor (C3aR), C3a elicits cellular responses (e.g., release of histamines from mast cells [12]). Of note, the role of $\mathrm{C} 3 \mathrm{a}$ is not consistently proinflammatory as a reevaluation emphasized (reviewed in [13]). Nevertheless, C3a plasma concentrations directly correlate with the severity of trauma and adumbrate the development of multi-organ dysfunctions [14].

If not stopped by the action of complement regulators (as it happens on healthy host surfaces), any initially produced C3b amplifies via the AP (auto-)amplification loop: membrane-bound $\mathrm{C} 3 \mathrm{~b}$ serves as basis for the formation of further $\mathrm{AP}$ convertases which generate more $\mathrm{C} 3 \mathrm{~b}$ molecules, thereby amplifying the $\mathrm{C} 3$ deposition exponentially. Increasing $\mathrm{C} 3 \mathrm{~b}$ densities deposited on surfaces bind and prime $\mathrm{C} 5$, thus preparing $\mathrm{C} 5$ to be cleaved by bimolecular convertase complexes, a crucial step for the onset of the terminal complement pathway [15-17]. Conversion of C5 leads to the release of the highly potent anaphylatoxin $\mathrm{C} 5 \mathrm{a}$ and $\mathrm{C} 5 \mathrm{~b}$, the initiating molecule of the membrane attack complex (MAC). Binding of $\mathrm{C} 5 \mathrm{~b}$ to the late complement proteins $\mathrm{C} 6, \mathrm{C} 7, \mathrm{C} 8$, and multiple copies of $\mathrm{C} 9$ can lead to integration of this complex into the cell membrane causing lysis due to osmotic flux [18]. When assembling of MAC is quenched by $\mathrm{S}$ protein (vitronectin) before insertion into a bilayer membrane, a soluble complex-denominated sC5b-9 is formed [19]. In contrast to $\mathrm{C} 3 \mathrm{a}$, two $\mathrm{C} 5 \mathrm{a}$ receptors (C5aR1 and C5aR2/ C5L2) are known. The role of C5aR2 is divergent as proinflammatory and anti-inflammatory properties are reported for C5aR2 [20, 21]. Under conditions of strong complement dysregulation, host cells can be affected by MAC possibly inducing apoptosis among other effects. While erythrocytes have been shown to be especially susceptible for MAC lysis [22], nucleated cells appear more resilient. Tutelar mechanisms of nucleated host cells include, for instance, shedding of MACs via microvesicle formation, thus reducing the harmful burden [23]. Next to cytolysis, also sub-lytic MAC concentrations have been shown to trigger important immunomodulatory functions, such as the release of the inflammatory mediators IL- 8 and MCP-1 or the upregulation of the adhesion molecule Pselectin which was demonstrated for human umbilical vein endothelial cells [24-26]. 


\section{Complement activation requires strict control mechanisms: the regulators}

These few examples illustrate the enormous potential of the complement effector functions and forebode their tight regulation. The assembly of lytic MAC pores can be intercepted by CD59 (protectin), a membrane-anchored complement regulator which disturbs the incorporation and inhibits the polymerization of the pore-forming C9 molecules. Interestingly, cell damage can trigger shedding of soluble CD59 (sCD59), evidenced by elevated plasma levels which were detected after acute myocardial infarction [27]. The concrete function of SCD59 as well as the degree to which its plasma concentration could be a useful biomarker in other clinical settings (e.g., trauma) has to be examined in prospective studies. Beside CD59, host cells are equipped with different other membrane-bound complement regulators. Since the convertase-mediated activation of the central proteins $\mathrm{C} 3$ and $\mathrm{C} 5$ is a crucial step in the cascade, convertases require tight regulation beyond the intrinsic convertase decay which occurs within minutes and disallows reformation of its components once separated. If their formation takes place on body's own surfaces, convertases are dissociated by the action of the decay accelerating factor (DAF, CD55), complement receptor $1(\mathrm{CR} 1, \mathrm{CD} 35)$, or soluble regulators bound to the host surface like factor $\mathrm{H}$ ( $\mathrm{FH}$; specific for the $\mathrm{AP}$ ) or the $\mathrm{C} 4 \mathrm{~b}$ binding protein (C4BP, specific for the CP/LP) [28, 29]. Consequently, $\mathrm{C} 3$ deposition and further downstream effector functions can be blocked which was previously shown, e.g., in vitro [30] and in vivo by the administration of recombinant DAF to pigs subjected to hemorrhagic shock. Decreased C3 deposition and organ damage correlated positively with animal survival in this model [31]. In another model in rats, early application of recombinant DAF after traumatic chest injury resulted in beneficial outcome regarding cytokine profile confirming a possible therapeutic role for recombinant DAF although the exact mode of action remains unclear and is still content of research $[30,32]$. Next to DAF, also CR1 decays convertases, completing the group of known membranebound molecules exhibiting decay accelerating activity. CR1 also harbors co-factor activity for factor I (FI)-mediated cleavage of $\mathrm{C} 4 \mathrm{~b}$ and $\mathrm{C} 3 \mathrm{~b}$ into $\mathrm{iC} 4 \mathrm{~b}$ and $\mathrm{iC} 3 \mathrm{~b}$ and further breakdown of products. Such inactivated opsonins lose their ability to form convertases but still function as ligands for a variety of complement receptors expressed on a wide range of immune cells. A putative therapeutical benefit of CR1 was demonstrated by the application of soluble CR1 (sCR1) into rats protecting nerves from early axon loss after crush injury [33]. The membrane co-factor protein (MCP, CD46) completes the "classical" surface-bound regulators. It serves as a co-factor for the FI-mediated inactivation of $\mathrm{C} 3 \mathrm{~b}$ and $\mathrm{C} 4 \mathrm{~b}$ [34]. Interestingly, declined MCP levels on neutrophils have been measured after trauma, implying a lower self-protection profile in this setting [35]. In sepsis, MCP participates in expediting the immune response by modulating the polarization and survival of macrophages [36]. Of note, beside its primary complement-related functions, MCP was described as a "pathogen magnet" [37]. Several viral as well as bacterial species were identified to employ MCP as a docking receptor to enter cells, among others the pathogenic bacterium Streptococcus pyogenes [38].

In addition to the described membrane-bound regulators, complement also comprises soluble regulators which stop inadequate complement consumption in the fluid phase and reinforce surface regulation by the membrane-fixed regulators. $\mathrm{C} 4 \mathrm{BP}$, the fluid phase regulator of the $\mathrm{CP}$, binds $\mathrm{C} 4 \mathrm{~b}$ and facilitates its degradation by FI and also decays the classical C3 convertase C4b2a [39, 40]. Interestingly, some pathogens specifically capture C4BP, thus probably evading the actions of the immune system [41]. C4BP has been shown to inhibit protein S (not to be confused with "S protein", see above), an important co-factor for the protein $\mathrm{C}$-mediated downregulation of the coagulation cascade [41]. By contrast, antithrombotic properties have been postulated for the most upstream soluble $\mathrm{C} 1$ inhibitor $(\mathrm{C} 1 \mathrm{INH})$ which controls the activation of C1. Application of C1INH in a murine model of traumatic brain injury displayed anti-inflammatory effects as well as reduced fibrinogen deposition and diminished vessel occlusion in comparison to sham-treated mice [42]. Interestingly, also an (complement) inactive form of C1INH has been demonstrated to protect from sepsis in a cecal ligation and puncture (CLP) mouse model [43]. The only known negative AP regulators in the fluid phase are $\mathrm{FH}$ and its splice variant factor H-like 1 (FHL-1). Both molecules share most of their functions which are co-factor activity for FI-mediated cleavage of $\mathrm{C} 3 \mathrm{~b}$ and decay accelerating activity for $\mathrm{C} 3 \mathrm{bBb}$ convertases. Since FH has improved host recognition properties in comparison with FHL-1 [44], the physiological need of FHL-1 is not completely clear so far and content of ongoing research [45]. In addition to FHL-1, the FH family also comprise several factor $\mathrm{H}-$-related proteins (FHRs) which share ligands with FH $[46,47]$. FHRs are expected to further fine-regulate the AP regulation by $\mathrm{FH}$, but the precise roles are still under investigation. One recent study shows that FHR-1 and FHR-5 interact with DNA and necrotic cells, thereby displacing FH and increasing opsonization and complement activation [48].

Taken together, the complement system is stringently controlled at different levels of the cascade, allowing attack when necessary and suppressing it when not appropriate. However, acute diseases like trauma, burn, or sepsis unbalance the cascade by triggering an overwhelming complement activation response initiated by the enormous abundance of DAMPs and/or MAMPs. This unbalanced response is further influenced by the altered expression level of specific plasma proteins (e.g., C-reactive protein (CRP), serum amyloid A, fibrinogen, haptoglobin) in the course of the acute phase response 
[49]. Among them, differences in the expression levels of central complement proteins have been reported as well: $\mathrm{C} 4$ and concomitantly CRP serum concentrations were significantly higher in patients with severe acute respiratory syndrome in comparison to the control group [50], and C3 and CRP levels correlated in subjects with unstable angina [51]. In turn, CRP can activate the classical pathway potentially increasing the complement dysregulation in acute diseases. One study could reveal that complement is even a driver of the general process of the acute phase response since human CRP transgenic mice deficient in C3 or C5 have been shown to attenuate LPS-induced upregulation of the CRP gene [52]. As the complement cascade also cross-talks with other physiological pathways like hemostasis [53,54], severe injuries do not only lead to dysregulation of the complement response but also offset the balance in other important effector systems.

\section{Thromboinflammation}

The intravascular innate immune system (IIIS) consists of the blood cascade system, namely the coagulation system, the kallikrein/bradykinin system (contact system), and the fibrinolytic system, in addition to the complement system which has been described in detail above. The IIIS is the humoral arm of the natural immune system, and 95\% of all animal species alive today rely on this line of defense which functions without involvement of T and B cells. A key function of the IIIS is to distinguish between self (healthy autologous cells), non-self (MAMPs), and/or altered self (DAMPs), but unlike the adaptive immune system, the IIIS can only differentiate itself from non-self at the species level and not at the individual level.

There are multiple points of contact and cross-talk between the systems within the IIIS, e.g., when a proteolytic enzyme which has been activated in one system can activate a substrate molecule within another system [55]. One example of high relevance for this article is the cleavage of complement components $\mathrm{C} 3$ and $\mathrm{C} 5$ to yield functional anaphylatoxins by non-canonical proteases. These include factors IXa, Xa, and thrombin as well as plasmin which are unleashed during activation of the coagulation and fibrinolytic system, respectively [56-58]. Cross-talk which occurs in the opposite direction is exemplified by MASP-1 and -2 which play significant roles in coagulation activity and can lead to fibrin formation in the absence of thrombin $[59,60]$.

However, research in this area has up to recently been very segregated, mainly for technical reasons. Consequently, many of the potential interactions have not been demonstrated, and altogether, their physiological relevance in different pathological settings is not always clear. The main caveat is that researchers in the various disciplines traditionally tend to use different anticoagulants according to the requirement of one system, but which may inactivate another system, thereby disabling studies of their interactions. Typically, complement activation is studied in serum where all coagulation activation is irreversibly inhibited. On the other hand, coagulation is monitored in citrate plasma because its activation can be restored by recalcification, but complement is activated and consumed under these conditions. This has led us and other colleagues to do studies in whole blood, preferably completely without soluble anticoagulants to enable mapping of interaction between various cascade systems and their target cells $[61,62]$.

The cascade system of blood is etiologically ancient and has an important function as a "waste disposal system" where recognition and removal of foreign substances and particles, including apoptotic and necrotic cells, are central. The proteins in the various cascades have a common origin, and parent molecules can often be identified in evolutionary early organisms such as sea urchins. The systems have been developed through gene duplications either through the two genome duplications that have taken place during evolution or through gene duplications taking place locally, which creates clusters of genes coding for proteins with similar functions. One poignant example is $\mathrm{C} 3[63,64]$ : a $\mathrm{C} 3$-like molecule is found early in evolution, and after two gene duplications, four homologous proteins are now found in vertebrates, i.e., C3, $\mathrm{C} 4, \mathrm{C} 5$, and also the proteinase inhibitor $\alpha 2 \mathrm{M}$ (with a similar mechanism of action). Local duplications have led to the cluster of genes for complement inhibitors found on chromosome 1 that encode FH, DAF, MCP, C4BP, etc. [65]. Similar duplications have taken place within other cascade systems, which is one explanation of the complexity of these cascade systems.

Activation of thromboinflammation is a driving force in several diseases and pathological conditions including trauma, burn injuries, and sepsis which are the main focus of this article and discussed in detail. Other clinically relevant conditions include ischemia-reperfusion injury (IRI) which may be triggered by thrombotic events such as cardiac infarction and stroke but also by therapeutic interventions like transplantation and cardiopulmonary bypass. The concept of thromboinflammation and various pathophysiological implications is discussed in detail in Ekdahl et al. [66].

\section{Trauma}

The complex innate immuno-pathophysiological response after trauma has recently been extensively reviewed on a crosstalking multiple organ level $[67,68]$. Concerning the basic principles of the complement response after trauma including the development of a temporary complementopathy, we refer to our latest review [24]. Here, we will mainly focus on the role of complement in the clinical setting summarizing 
meaningful studies in higher species (non-human primates) in addition to clinical therapeutic aspects in man.

Caused by the abovementioned DAMP/MAMP- and coagulation-driven mechanisms, any trauma leads to local complement activation and, if the tissue injury is severe enough, also to systemic activation. In the case of lifethreatening polytrauma, rapidly enhanced $\mathrm{C} 3 \mathrm{a} / \mathrm{C} 3$ ratios as well as $\mathrm{C} 5 \mathrm{a}$ and sC5b-9 plasma concentrations in patients have been reported by several groups [69-73]. Based on an excessive complement activation, a drop in complement functional performance as a temporary complement dysfunction (or "traumatized complement") has been postulated, likely setting the patient at an enhanced risk of infectious complications $[24,71,72]$. On the cellular level, neutrophils have lost their C5aR1 and C5aR2 and altered their complement regulatory proteins after severe tissue injury which has been associated with several neutrophil dysfunctions [35, 74]. In the intensive care unit setting, loss of C5aR1 on neutrophils has even been proposed as a reliable predictive marker for development of subsequent infectious complications [75]. However, it is still a matter of debate whether and to which extent exogenous proteases, e.g., from the coagulation or fibrinolytic cascade, contribute to early complement activation after trauma [58, 76-80]. Here, further research is needed, especially to determine the clinical implications of noncanonical complement activation by tissue trauma.

Excessive complement activation after severe tissue injury and the associated multidimensional immune, cellular, and microvesicle functions provide some rationale to target specific complement factors for more favorable cell, organ, and clinical outcomes [81]. Nevertheless, it has to be emphasized that not only inhibition but also complement reconstitution strategies may be helpful depending on the immune status, the targeted factor, and/or the complement pathway involved. For example, fresh frozen plasma, a major component of early resuscitation intervention in polytrauma patients with hemorrhagic shock and coagulation disorders, contains not only various clotting factors but also multiple complement components, such as $\mathrm{C} 3$ and C5. However, the level of active complement in fresh frozen plasma depends on donor, age, and storage factors, making it difficult to correlate clinical improvement with supplement complement functionality via plasma infusions [82]. Moreover, preparations of packed platelets were demonstrated to contain anaphylatoxins, which even increase with storage time [83]. Besides transfusion of blood products, patients often receive tranexamic acid early after polytrauma to treat bleeding disorders by inhibiting plasmin and thus hyperfibrinolysis. This lysine analogue also significantly reduced complement activation as reflected by decreased systemic sC5b-9 (also called terminal complement complex, TCC) concentrations in patients with hemorrhagic shock [84]. Mechanistically, either a direct inhibition of complement activation or an indirect inhibition occurs via blockade of plasmin which in turn loses its $\mathrm{C} 3$ or $\mathrm{C} 5$ cleaving ability.

Excessively generated complement activation products such as $\mathrm{C} 3 \mathrm{a}$ and $\mathrm{C} 5 \mathrm{a}$ can be cleared by hemoadsorbance, an intervention which has shown some protective effects in major surgery so far [85]. In contrast to a global reduction of circulating complement cleavage products, a few targeted complement inhibition strategies have been evaluated in humans and in monkeys. $\mathrm{C} 1$ inhibition was applied in trauma patients with femur fracture with the primary read-out for changes in IL-6 concentrations reflecting systemic inflammation [86]. However, based on a heterogenous cohort and recruitment challenges, this study has been closed, and no conclusion could be drawn so far. Effective blockade of the central C3 component by $\mathrm{Cp} 40$ (a member of the compstatin family) in a delayed manner, i.e., $30 \mathrm{~min}$ after induction of a severe trauma/hemorrhagic shock (MAP $30 \mathrm{mmHg}$ for $60 \mathrm{~min}$ ), significantly reduced the inflammatory response and improved hemodynamics, barrier, and several organ functions [87]. On the $\mathrm{C} 5$ level, in a non-human primate hemorrhagic shock/ polytrauma model, the authors confirmed the clinical findings of elevated C5 cleavage products and tested ex vivo some small peptide inhibitors for C5 cleavage [88]. However, no in vivo inhibition has been performed so far in such a model. To our knowledge, selective inhibition of MAC formation has not been performed yet. In conclusion, although complement seems a major driver of the posttraumatic inflammatory response, there is a clear lack of clinical studies targeting central complement components or neutralizing the excess of generated complement activation products after trauma and during hemorrhagic shock. It is tempting to speculate that a remaining, albeit low, activity of complement for opsonization of pathogens and clearance of infected or damaged cells is desirable in the context of trauma to prevent viral reactivation and infectious complications and to aid the reconstitution of tissue homeostasis [89].

\section{Burn}

Burn as physical injury is the fourth most common trauma worldwide [90]. Primarily, the term "burn" is associated with fire and injuries caused by hot substances. Beyond that, radioactive and electric injuries as well as caustic chemicals may also elicit burn-like wounds. Even cold wounds have been shown to release comparable cytokine profiles although there are important morphological differences in comparison to heat wounds [91]. Evaluation of the burn dimension plays a crucial role in the acute medical care. On the one hand, burn severity is categorized depending on the wound depth ranging from an epidermal first-degree over a second- and third-degree to a fourth-degree full-thickness burn [92]. On the other hand, an important parameter is the affected total body surface area 
(TBSA) which has been shown to directly correlate with morbidity and mortality. Patients experiencing $60 \%$ TBSA or more displayed increasing hyper-inflammatory reactions as well as a drastic diminished cardiac function [93]. Such hyper-inflammatory responses are predestinated to show a strong activation of the complement system.

Indeed, its involvement has long been known and it sets in rapidly. Sriramarao and DiScipio detected C3 and FH deposition in murine blood vessels in and proximal to the burn site within 10 min of injury [94]. Beside the mechanical leakage from the wound, locally an enhanced vascular permeability was recognized to occur quickly post-burn resulting in an accumulation of water, protein levels, and salt in the interstitium. In a rat model, this effect was shown to be clearly complement dependent since it could be attenuated by prior complement depletion [95]. In addition to these local processes, complement also triggers fast and delayed systemic burden reactions. For instance, intravascular hemolysis of red blood cells or at least an elevated osmotic fragility was recognized early after burn as a consequence of oxygen radicals released from complement-activated neutrophils [96] (see Figure 1). Lung injuries in rats have been displayed to evolve hours after burn in accordance with alterations in complement levels [97, 98]. Complement activation was revealed to occur mainly via the AP evidenced by a massive drop of the hemolytic activity in the alternative pathway (AH50) in the first hours following trauma, while the hemolytic activity of the classical pathway (CH50) remained normal or even supranormal [99]. C3 plasma levels are inversely correlated with the burn severity and could be used as a prognostic marker [100]. However, in the course of 2 weeks after burn, AH50 and CH50 increase concomitant with the presence of complement proteins (e.g., $\mathrm{C} 3$ and $\mathrm{C} 4$ ). Having reached a small plateau after 7 days, the further increase of these parameters was statistically more pronounced in survivors compared to non-survivors [101]. Anaphylatoxin plasma concentrations were reported to raise immediately after burn. C3a levels peaked 1 week after burn injury, whereas the literature is not consistent for C5a levels over the first weeks $[102,103]$. Remarkably, fluctuations of C3, C3d, and factor Ba concentrations were observed even up to 1 year post-burn, and long-term elevated $\mathrm{C} 3 \mathrm{a} / \mathrm{C} 3$-ratio baseline levels indicate chronic inflammatory conditions $[104,105]$. While a clear relationship between anaphylatoxin concentrations and the development of septic conditions could not be identified [103], elevated C5a plasma levels have been shown to correlate with neutrophil dysfunctions in terms of altered migratory behavior and diminished chemotactic responsiveness to activated serum [102]. Interestingly, complement depletion prior to burn injury by the application of cobra venom factor in a murine burn model lowered mortality rate in the first $24 \mathrm{~h}$ post-burn [99]. It is therefore doubtless that complement is a major driver in the pathophysiology of burn not only locally but also systemically (reviewed in [105]). This implicates complement as a potential therapeutic target which is going to be discussed in the following.

Starting from the very top of the complement cascade, application of the $\mathrm{C} 1 \mathrm{INH}$ displayed protective effects against ischemic lesions following burn in a porcine model. Therapeutic intervention with C1INH could prevent the damage of subdermal spheres [106]. In comparison to the control

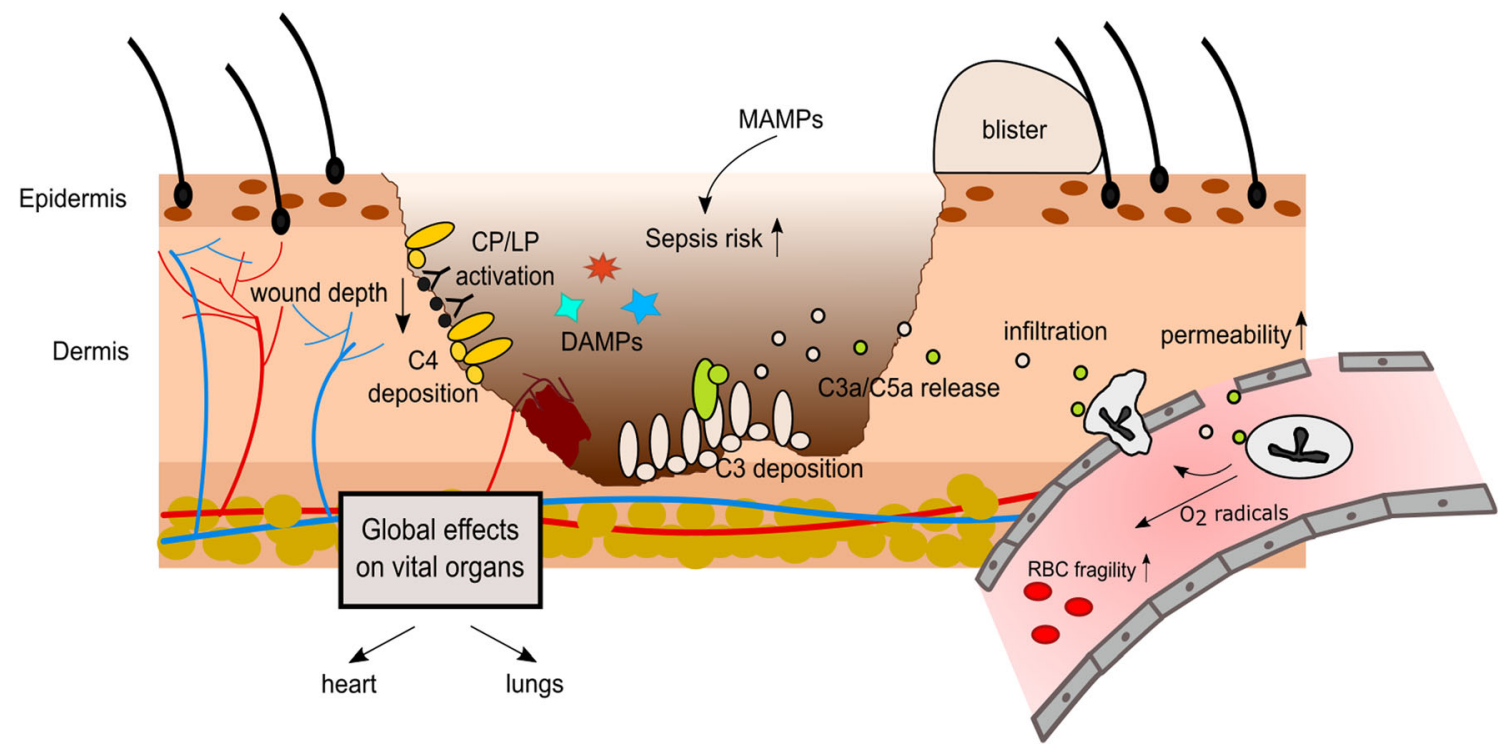

Figure 1. Complement activation after burn injury. Burn injury triggers the release of damage associated molecular patterns (DAMPs) and increases the susceptibility for microbial associated molecular pattern (MAMP) exposure, thus elevating the risk for sepsis. Complement activation takes place at the burn site, locally increasing vascular permeability and promoting infiltration of immune cells. Massive anaphylatoxin release also induces widespread effects, especially affecting the lungs and the heart. CP: classical pathway, LP: Lectin pathway, RBC: red blood cell. 
group, early-stage complement blockage by C1INH could reduce granulocyte attachment to endothelial cells as well as thrombus formation in the lower dermal vasculature. Moreover, systemic application of $\mathrm{C} 1 \mathrm{INH}$ attenuated post-burn shock-induced organ alterations as well as gutderived bacterial translocation in pigs exposed to a seconddegree skin burn [107, 108]. Beside these short-term effects, recently a treatment with C1INH up to 15 days post-burn and its long-term consequences concerning wound healing was investigated [109]. Despite reduction of the local inflammation in the wound, long-term wound healing as measured by necrosis, re-epithelialization, and wound contraction was not affected. Prolonged administration of C1INH also diminished burn-induced infiltration of inflammatory cells (e.g., macrophages) and markers (e.g., C3) not only in the local wound but also in ventricles or atria of the heart [110]. This is of highest importance since burn severity is directly linked to cardiac dysfunctions characterized by tachycardia, myocardial oxygen consumption, and an increased cardiac output which persist for up to 2 years or even longer as measured in children with $\geq 40 \%$ TBSA [111]. Beside elevated levels of catecholamines, which were considered to be the major driver in this study, the engagement of C5a with its receptor on cardiomyocytes was revealed to account for a substantial part in cardiac dysfunctions in other settings [112]. Indeed, C5aR expression increased time-dependently after burn up to $48 \mathrm{~h}$ in cardiomyocytes [113]. In a full-thickness scald injury rat model, Hoesel et al. demonstrated benefits of an anti-C5a therapy by significantly attenuating cardiac dysfunction in vivo and also in vitro on isolated cardiomyocytes. LPS treatment of isolated cardiomyocytes disclosed impaired contractility, an effect that could be partially reversed when the rats were pretreated with an anti-C5a inhibitor [113]. Similar protective benefits of an anti-C5a treatment were also shown for lungs in burn-injured rats [114]. Blocking C5a resulted in a significant reduction of ICAM-1 upregulation and caused in turn a reduction in neutrophil accumulation in the lung tissue.

Burn injury is accompanied by an additional local damage caused by the overwhelming acute inflammatory processes. This was attributed to the recognition of self-antigens by natural IgM antibodies and is crucial for the determination of the wound depth [115]. Since this could activate the CP, Suber et al. assayed the wound healing in C4-/- mice in comparison to wildtype mice. While in wildtype mice the burn injury wound healing process was characterized by scarring and hair loss, C4-/- mice healed without scar formation and hair loss and revealed attenuated neutrophil infiltration [115].

Taken together, these observations clearly indicate that the role of complement in burn injury is multidimensional, eliciting effects not only locally but also systemically having tremendous impact on the functionality of several vital organs.
Promising results concerning complement inhibition in animal studies have not yet been transferred into human. Moreover, to our knowledge, no studies investigated direct blockage of the central complement proteins, although C5 inhibitors are clinically approved and in case of $\mathrm{C} 3$ inhibitors clinically investigated.

\section{Sepsis}

By the past definition of sepsis, a sportsman working out excessively could have easily been characterized as suffering from a systemic inflammatory response syndrome (SIRS) or sepsis. People excising exhaustively feature all signs of a SIRS which is defined by tachycardia, tachypnoea, elevated temperature, and leukocytosis. If the sportsman would have brushed his teeth at the end of the sportif performance, e.g., at the finishing line of a marathon course, he would even temporarily face a bacteremia and thus by definition would be in full-blown sepsis which had been defined as SIRS plus bacteremia [116].

However, introducing a new definition for sepsis that focuses more on the multi-organ level has solved the dilemma of characterizing exercising athletes as septic patients. In 2016, sepsis has been redefined as a life-threatening organ dysfunction caused by a dysregulated host response to infection [117]. A quick diagnosis of life-threatening sepsis at the bedside can be accomplished by the quick sequential organ failure assessment score (qSOFA). This score focuses on the dysfunction of three vital organs: the brain, heart, and lungs by determination of mental alterations, drop in systemic blood pressure below $100 \mathrm{mmHg}$, and enhancement of the respiratory rate $>22 / \mathrm{min}$. Applying these new criteria, the proactive sportsman in the example given above will now not any longer be classified to be in full-blown sepsis nor in organ failure. Of note, this new definition resulted in a relatively high sensitivity and specificity for enhanced mortality risk by sepsis [117]. In consequence, translational meaningful research on complement will need to shift from research on systemic parameters of complement activation and actions, e.g., of anaphylatoxins plasma levels, toward a more organ-targeted approach (Figure 2). Thus, against the background of the clinical situation, we will cover the role of complement during sepsis not only on the systemic level but also focus on the three qSOFA-assessing organs: the brain, lungs, and heart.

On a molecular level, complement activation by MAMPs results in generation of the anaphylatoxins $\mathrm{C} 3 \mathrm{a}$ and $\mathrm{C} 5 \mathrm{a}$ which can induce all classical signs of local inflammation (dolor, rubor, calor, tumor, and functiolesa) and are involved in systemic inflammation as well. Multiple experimental and clinical studies have demonstrated significant systemic complement activation during sepsis [118-120]. In humans, enhanced C3a, C5a, and 
Figure 2. From acute injury to multi organ dysfunction. Acute injuries with distinct DAMP/MAMP profile can induce an unbalanced complement activation not only locally but also systemically. A tight linkage to other systems of the innate immune system means that these branches are eventually also activated resulting in a state often called thromboinflammation. The consequences are multidimensional, eliciting effects on various vital organs and worsen the patient's outcome. The sequential related organ failure assessment score (SOFA) and especially the quick SOFA (qSOFA, comprising the organs heart, CNS and lungs) provides a basis for the evaluation of a patient's septic state. MODS: multi organ dysfunction syndrome.

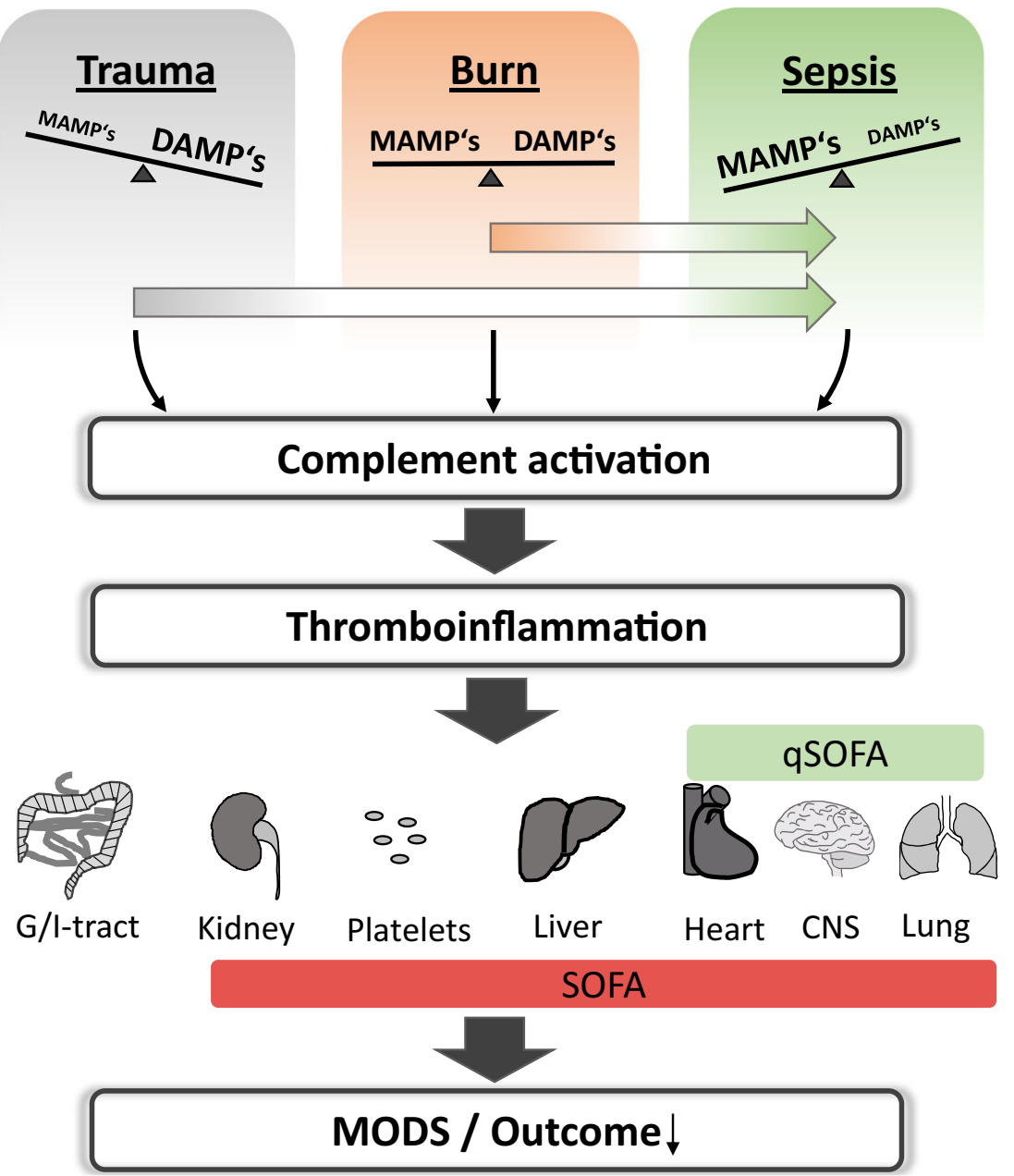

sC5b-9 concentrations in the blood and corresponding loss of the $\mathrm{C} 5 \mathrm{aR} 1$ and $\mathrm{C} 5 \mathrm{aR} 2$ have been proposed as driver for sepsis-induced complications and multiple organ failure [120-123]. A recent translational study has shown that C5a could activate a "metabolic switch" in neutrophils as first line of defense resulting in an enhanced intracellular $\mathrm{pH}$ and glycolytic flux with mounting of a lactic acidosis in the extracellular microenvironment [74]. Remarkably, lactic acidosis could not only be caused due to an oxygen debt but rather to an activated innate immune response. Furthermore, C5a seems also to form a procoagulant platform on leukocytes by activating a "coagulatory switch" [124]. C5a seems to link the innate and adaptive immune response during the sepsis course as it also induces detrimental effects on natural killer $\mathrm{T}$ and natural killer cells [125].

Taken together, complement activation in sepsis is a major driver for the thromboinflammatory response. Besides the systemic effects, complement may act locally, i.e., compartmentalized at various organ levels. The focus in the following section is set on the main organs contributing to the clinical definition of sepsis: the brain, heart and lungs.

\section{Complement interactions in the brain}

The complement system is an integral part of the cerebral innate immune system $[126,127]$ and can also be recruited from systemic circulation in case of a damaged blood-brain barrier (BBB) [128].

In a murine sepsis model to study the role of complement in brain pathology, LPS injection resulted in an enhanced cerebral expression of glial fibrillary acidic protein (GFAP), tolllike receptor (TLR) 4, pro-inflammatory molecules, Aktmediated apoptotic events, and increased gliosis. All of these observations were ameliorated in mice overexpressing the murine complement inhibitor, CR1-related y (Crry-tg) [129]. Further downstream, the anaphylatoxin $\mathrm{C} 3 \mathrm{a}$ has recently been investigated after LPS injection into neonatal rodents [130]. The authors showed by immunofluorescence enhanced levels of $\mathrm{C} 3 \mathrm{a}$ and $\mathrm{C} 3 \mathrm{aR}$ in the periventricular white matter of septic animals. It was proposed that LPS can induce generation of C3a and IL-1 1 in astrocytes and microglia which will bind to oligodendrocytes and activate the AKT signalling pathway which inhibits the downstream WNT/ $\beta$-catenin signalling pathway, finally leading to axonal hypomyelination of the 
periventricular white matter. Remarkably, intraperitoneal application of a C3aR antagonist (SB 290157) reversed all the sepsis-induced alterations of the white matter, indicating $\mathrm{C} 3 \mathrm{a}$ as a central player in septic cerebral dysfunction [130]. In contrast, in a murine model of lethal endotoxin shock, C3a-specific expression in the central nervous system (CNS) (without the requirement of previous complement activation) in C3a/GFAP transgenic mice was more protected than $\mathrm{C} 3 \mathrm{aR}$-deficient mice (C3aR-/-) or wildtype littermates [131]. Moreover, C3a/ GFAPxC3aR-/- hybrids were also resistant against endotoxin shock, suggesting some beneficial effects of local, cerebral C3a [131]. In this context, C3a has been shown capable to inhibit excitotoxicity-mediated neuronal cell death [132].

In experimental murine sepsis induced by CLP, a considerable blood-brain barrier (BBB) breakdown was found which, of note, was almost completely inhibited by blockade of systemic C5a. Furthermore, sepsis-caused pituitary gland dysfunction was improved by anti-C5a treatment [133]. These findings are supported by a report demonstrating that $\mathrm{C} 5 \mathrm{a}$ drives the BBB breakdown in a systemic lupus model [134]. However, some debate remains on whether C5a blockade is beneficial or detrimental for sepsis-associated brain dysfunction [135].

In the clinical setting, sepsis-induced brain dysfunction as determined by altered neuroinflammatory markers, magnetic resonance imaging (which revealed morphological alterations in approximately $2 / 3$ of the patients), and clinical parameters (such as the Glasgow outcome score extended) has shown enhanced $\mathrm{C} 4 \mathrm{~d}$ but significantly reduced systemic $\mathrm{iC} 3 \mathrm{~b}$ and C5a concentrations in patients with cerebral lesions [136]. However, the local complement activation level in the brain tissue was not determined. In an experimental animal model setting, this question was investigated previously by this group: in rodent CLP sepsis, significantly enhanced levels of $\mathrm{C} 5 \mathrm{a}, \mathrm{C} 5 \mathrm{aR}$, and $\mathrm{C} 3 \mathrm{aR}$ were measured in brain samples of septic animals up to 10 days post-infection [137].

An interesting therapeutic approach to improve the energy support has recently been published: mitochondrial transplantation in CLP septic mice improved not only bacterial clearance but also organ performance and survival. A hypothesis-free expression profiling revealed complement and coagulation factors as central contributors to the induced changes [138].

Taken together, complement activation and action in the brain during sepsis seem to alter a delicate balance of proand anti-inflammatory effects and requires further mechanistical and clinical research before clinical translation appears feasible.

\section{Complement interactions in the heart}

For more than a quarter of century, complement activation has been postulated to alter the heart function and subsequently the macro- and microcirculation [139]. After exposure of human healthy volunteers to LPS, as expected, the blood pressure dropped, and both, the heart rate and temperature, increased time-dependently. However, application of C1INH failed to alter these hemodynamic alterations although less pro- and more anti-inflammatory mediators were detected systemically, indicating that $\mathrm{C} 1$ activation did not alter heart function in this setting [140]. In canines, injected with Escherichia coli (E. coli), the genetic absence of $\mathrm{C} 3$ aggravated the hemodynamic effects with compromised ejection fraction of the left ventricular [141]. In contrast to that, in baboons being exposed to $E$. coli, the reduction in mean systolic arterial pressure (as sepsis sign) was greatly improved among other organ functions by blockade of $\mathrm{C} 3$ by compstatin even when applied in a delayed fashion up to $5 \mathrm{~h}$ post-infection [142]. Regarding the C5 level, the application of the macrocyclic peptide inhibitor of C5 cleavage (RA101295) improved the hemodynamic readouts [143]. Further mechanistic insights of the interaction between complement activation products and the heart were obtained in vivo in rodent sepsis models and in vitro with cardiomyocytes [112]. The mosaic picture of these studies suggests that systemic C5a interacts with the C5aR1 and C5aR2 on cardiomyocytes [144, 145] alters the membrano-electrophysiological features [146] and induces intracellular signalling [147]. In turn, key calcium-regulatory proteins (such as sarco-/endoplasmic reticulum $\mathrm{Ca} 2+-$ ATPase), transporters, and channels become dysfunctional all of which lead to an intracellular calcium disbalance and contractory dysfunction $[112,146]$. In association with released histones (presumably from activated leukocytes), C5a can activate the NLRP3 inflammasome in cardiomyocytes and contribute to the local cardio-suppressive inflammatory milieu [148, 149] [150]. Of note, blockade of the C5a-C5aR interaction maintained the $\mathrm{C} 5 \mathrm{aR}$ expression and hemodynamic performance of the heart $[112,146]$.

On the MAMP sensing site, TLRs are mainly involved in mediating inflammation and organ injury during sepsis. Concerning the heart, TLR signalling is involved in sepsisinduced functional suppression [151]. Activation of TLR2, TLR3, and TLR4 resulted in robust expression of complement FB by cardiomyocytes. In murine CLP sepsis, FB was indeed enhanced in the heart and associated with cardiac deposition of C3 fragments [152]. Moreover, absence of FB resulted in some protective cardiac function and improved the outcome. The absence of MyD88 as common adaptor protein of most TLRs attenuated the upregulation of $\mathrm{FB}$ and $\mathrm{C} 3$ in cardiomyocytes [152]. These findings support a combined inhibition approach of both, the TLR and complement activation axis. Indeed, blockade of CD14 as co-receptor along with TLR4 for LPS and synchronic inhibition of $\mathrm{C} 5$ in a pig sepsis model revealed some protective effects on the generation of cytokines from cardiac cells [153]. However, further clinically meaningful functional hemodynamic data need to be 
established. In addition, the interplay between adrenoreceptors as drivers of the heart performance and complement receptors, such as the $\mathrm{C} 1$ receptor and $\mathrm{C} 5 \mathrm{aR} 1$, needs further mechanistic elucidation [154].

Taken together, broad evidence indicates that $\mathrm{C} 3$ and $\mathrm{C} 5$ activation is central in development of cardiac dysfunction during sepsis, and it is tempting to speculate that blockade of these activation products will improve the cardiac performance as key component of septic complications also in translational settings.

\section{Complement interactions in the lungs}

The lungs are main actors and targets of the immunepathophysiological response during sepsis and therefore a site of massive complement activation. Pulmonary thromboinflammation, in principle investigated more than two decades ago $[155,156]$, is in renaissance due to the current SARS-CoV-2-induced pulmonary pathology. Systemic and pulmonary complement, especially $\mathrm{C} 3$ and $\mathrm{C} 5$ activation, has been proposed as reasonable therapeutic targets which is under ongoing clinical assessment [157-159].

Multiple experimental data sets were collected in animal models of sepsis demonstrating morphological and respiratory changes [160]. Accordingly, the following principal sequelae can occur as briefly outlined: MAMP-induced complement activation leads to $\mathrm{C} 3 \mathrm{a}$ and $\mathrm{C} 5 \mathrm{a}$ liberation, which upregulates expression of pulmonary endothelial adhesion molecules (e.g., selectins) and thereby recruits neutrophils to the alveolar space. Upon activation (again by anaphylatoxins), these first responder cells release more inflammatory chemo- and cytokines and thereby recruit more inflammatory cells. Clearance of bacteria is accomplished by cellular activation and subsequent release of proteases and mounting of an oxidative burst, all of which also damage host tissue and the air-blood barrier. The resulting pulmonary inflammation and protein/water leakage leads to difficulties in oxygen and carbon dioxide diffusion which increasingly generate an oxygenation problem, clinically manifested as respiratory dysfunction or even failure.

Concerning deployment of complement therapeutics during experimental sepsis, complement depletion [161], C1 inhibition [162], specific blockade of C5a [118, 163], C5aR1 [164], genetic deficiency in C5 [165], or genetic absence of C6 $[166,167]$ have been demonstrated to improve sepsisinduced pulmonary inflammation on a morphological and/or functional level.

In contrast, in the case of $\mathrm{C} 3$, two independent reports in murine sepsis models suggested that application of C3 will support pulmonary clearance and improve respiratory function and outcome during sepsis $[141,168]$. In line with this, genetic absence of $\mathrm{C} 3$ leads to signs of pulmonary injury and multiple organ injury, and general outcome during sepsis is much worse than in wildtype littermates indicating overall protective effects of $\mathrm{C} 3$ in case of early bacterial sepsis [169, 170].

In clinical sepsis, it is established that patients reveal enhanced systemic concentrations of complement activation products such as $\mathrm{C} 3 \mathrm{a}$ and $\mathrm{C} 5 \mathrm{a}$ with inconclusive reports concerning their reliability to predict development of pulmonary dysfunction, clinically manifested as acute lung injury (ALI) and acute respiratory distress syndrome (ARDS) [120, 171-173]. Enhancement of pulmonary alveolar-capillary permeability has been determined in patients after trauma and with sepsis who were at risk to develop ARDS. Elevated plasma levels of $\mathrm{C} 3 \mathrm{a}_{\text {desarg }}$ correlated somehow with the air-blood barrier leakage [173]. In line, deposition of immune complexes along with $\mathrm{C} 3$ has been suggested in one human autopsy study as a pathomechanism of sepsis-induced multiple organ failure including the lungs [174]. Similar findings were reported in septic patients suggesting that both the classical and alternative pathways are activated before the onset of ARDS [175]. This was evidenced by the enhanced systemic appearance of the $\mathrm{C} 1 \mathrm{rC} 1 \mathrm{~s}-\mathrm{C} 1 \mathrm{INH}$ complex (derived from CP activation) and $\mathrm{C} 3 \mathrm{~b}$-properdin complex (derived from AP activation) concomitant with the sC5b-9 2 days prior to ARDS [175].

Regarding therapeutic strategies, the application of antiC5 $\mathrm{a}_{\text {desarg }}$ antibodies in non-human primates challenged with E. coli resulted in significantly improved oxygenation and decreased extravascular lung water in comparison to the non-treated septic group and, thus, attenuated septic ARDS [176]. In the same model, septic monkeys showed a rapid activation of systemic complement (with depletion of $\mathrm{C} 3$ and $\mathrm{C} 5$ and generation of $\mathrm{C} 3 \mathrm{a}$ and $\mathrm{C} 5 \mathrm{a}$ ) which was accompanied by a significant fall in peripheral leukocyte count and a significant increase in the pulmonary sequestration of leukocytes 15 min post-infection [177, 178]. In baboons with E. coli sepsis-induced ALI, blockade of C3 by compstatin significantly improved the acute alveolar inflammation as confirmed by diminished micro thrombosis, leukocyte infiltration, and capillary leakage. Of note, anti-C3 treatment also influenced extracellular matrix remodelling by attenuating collagen deposition and the development of fibrosis [142, 179].

Studies on therapeutic interventions in humans with septic respiratory failure are rare. A previous study on seven mechanically ventilated patients with streptococcal toxic shock, who were treated with $\mathrm{C} 1 \mathrm{INH}$, revealed a significant improvement of the capillary leakage syndrome in all but one patient [180]. One recent study applied a C5a antibody (InflaRx) to septic patients but did not report significant improvement on the respiratory function. However, since the clinical development of complement therapeutics in the respiratory field may become boosted by the current SARS-CoV-2 pandemic, further deployment in the field of sepsis is to be expected. 


\section{Conclusion}

The complement cascade is the major effector arm of the molecular innate immune system and interacts, involving multiple of its activation products, with several other branches of the immune system as well as the key regulatory circuits which serve tissue homeostasis and hemostasis. As the complement system constantly probes self, altered, and foreign surfaces for their potential to inflict harm, it comes as no surprise that substantial or even exuberant complement activation is a consequence of several traumatic injuries like trauma, burn, and sepsis. All these conditions are characterized by massive tissue damage which triggers strong complement activation. Thus, complement activation in these conditions usually exceeds the checkpoints that separate the noninflammatory proximal complement cascade producing $\mathrm{C} 3$ activation products from the inflammatory terminal pathway which liberates the potent anaphylatoxin $\mathrm{C} 5 \mathrm{a}$ and initiates MAC formation. In vivo evidence from animal studies and clinic settings demonstrates that exuberant complement activation in these conditions participates in causing systemic inflammation ultimately leading to organ failure. However, knowledge on what complement pathways or activation products are exactly driving detrimental inflammation leading to organ dysfunction is still sparse. Progress at this end is hampered by inconsistent findings reported in the literature which are based on different animal models and the (so far) rather sparsely available clinical studies investigating in humans. A further complicating factor in delineating how complement activation could be best intercepted therapeutically in these conditions is that local activation in tissues has been described to drive other physiological pathways than systemic complement activation. Clearly more research is necessary to further our understanding when, where, and for how long complement is best inhibited for alleviating morbidity and mortality in these complex clinical conditions. Cumulating evidence indicates that the terminal pathway (or specific parts thereof - e.g., anaphylatoxin C5a) is one of the most promising/ best documented complement pathways to be interfered with in future translational studies. However, in some disease models, inhibition of proximal complement pathways has resulted in remarkable benefits calling for further studies that dissected the role of the many different complement activation products upstream of $\mathrm{C} 5$ activation (e.g., C3a, C3b, iC $3 b$, $\mathrm{C} 3 \mathrm{dg}, \mathrm{C} 4 \mathrm{a}, \mathrm{C} 4 \mathrm{~b}, \mathrm{iC} 4 \mathrm{~b})$ in trauma, burn, and sepsis.

\footnotetext{
Abbreviations AH50, Hemolytic complement activity of the alternative pathway; ALI, Acute lung injury; AP, Alternative pathway; ARDS, Acute respiratory distress syndrome; ATP, Adenosine triphosphate; $\mathrm{BBB}$, Blood-brain barrier; C1INH, C1 inhibitor; C4BP, C4b-binding protein; CH50, Hemolytic complement activity of the classical pathway; CLP, Cecal ligation and puncture; CNS, Central nervous system; CR1, Complement receptor 1 (CD35); CRP, C-reactive protein; Crry-tg,
}

Complement receptor 1-related gene/protein y; CP, Classical pathway; Cp40, C3 peptide inhibitor of the compstatin family; DAF, Decay acceleration factor (CD55); DAMP, Damage-associated molecular pattern; DNA, Deoxyribonucleic acid; E. coli, Escherichia coli; FB, Factor B; FH, Factor H; FHL-1, Factor H-like 1; FHR, Factor H related; FI, Factor I; GFAP, Glial fibrillary acidic protein; Ig, Immunoglobulin; IIIS, Intravascular innate immune system; IRI, Ischemia-reperfusion injury; LP, Lectin pathway; LPS, Lipopolysaccharide; MAC, Membrane attack complex; MAMP, Microbe-associated molecular pattern; MAP, Middle artery pressure; MASP, Mannan-binding lectin-associated serine protease; MCP, Membrane co-factor protein (CD46); MCP-1, Monocyte chemotactic protein 1; mmHg, Millimeter of mercury; MyD88, Myeloid differentiation factor 88; qSOFA, Quick sequential related organ failure assessment score; sC5b-9, Soluble C5b-9 complex; SIRS, Systemic inflammatory response syndrome; TBSA, Total body surface area; TCC, Terminal complement complex; TLR, Toll-like receptor

Acknowledgements This review was supported by the CRC 1149 A01 (INST 40/479-2) and B02 (INST 40/487-2), the Swedish Research Council (2016-01060, 2016-04519, 2020-05762), the Swedish HeartLung Foundation (HLF 2020-0398), and by faculty grants from Linnaeus University. Open access funding is enabled and organized by Projekt DEAL.

Funding Open Access funding enabled and organized by Projekt DEAL.

\section{Declarations}

Conflict of interest The authors declare no competing interests.

Open Access This article is licensed under a Creative Commons Attribution 4.0 International License, which permits use, sharing, adaptation, distribution and reproduction in any medium or format, as long as you give appropriate credit to the original author(s) and the source, provide a link to the Creative Commons licence, and indicate if changes were made. The images or other third party material in this article are included in the article's Creative Commons licence, unless indicated otherwise in a credit line to the material. If material is not included in the article's Creative Commons licence and your intended use is not permitted by statutory regulation or exceeds the permitted use, you will need to obtain permission directly from the copyright holder. To view a copy of this licence, visit http://creativecommons.org/licenses/by/4.0/.

\section{References}

1. Hietbrink F, Koenderman L, Rijkers G, Leenen L (2006) Trauma: the role of the innate immune system. World J Emerg Surg WJES 1:15. https://doi.org/10.1186/1749-7922-1-15

2. Haagsma JA, Graetz N, Bolliger I et al (2016) The global burden of injury: incidence, mortality, disability-adjusted life years and time trends from the Global Burden of Disease study 2013. Inj Prev J Int Soc Child Adolesc Inj Prev 22:3-18. https://doi.org/10. 1136/injuryprev-2015-041616

3. James SL, Lucchesi LR, Bisignano C et al (2020) Epidemiology of injuries from fire, heat and hot substances: global, regional and national morbidity and mortality estimates from the Global Burden of Disease 2017 study. Inj Prev 26:i36-i45. https://doi. org/10.1136/injuryprev-2019-043299

4. Binkowska AM, Michalak G, Pilip S et al (2018) The diagnostic value of early cytokine response in patients after major trauma preliminary report. Cent Eur J Immunol 43:33-41. https://doi.org/ 10.5114/ceji.2018.74871 
5. Thornhill R, Strong D, Vasanth S, Mackenzie I (2010) Trauma sepsis. Trauma 12:31-49. https://doi.org/10.1177/ 1460408609356828

6. Nesargikar PN, Spiller B, Chavez R (2012) The complement system: history, pathways, cascade and inhibitors. Eur J Microbiol Immunol 2:103-111. https://doi.org/10.1556/EuJMI.2.2012.2.2

7. Afshar-Kharghan $\mathrm{V}$ The role of the complement system in cancer. J Clin Invest 127:780-789. https://doi.org/10.1172/JCI90962

8. Ruf W (2019) Links between complement activation and thrombosis. Blood 134:SCI-S40. https://doi.org/10.1182/blood-2019-121113

9. Mastellos DC, Deangelis RA, Lambris JD (2013) Complementtriggered pathways orchestrate regenerative responses throughout phylogenesis. Semin Immunol 25:29-38. https://doi.org/10.1016/ j.smim.2013.04.002

10. Ricklin D, Lambris JD (2013) Complement in immune and inflammatory disorders: therapeutic interventions. J Immunol 190: 3839-3847. https://doi.org/10.4049/jimmunol.1203200

11. Fromell K, Adler A, Åman A et al (2020) Assessment of the role of $\mathrm{C} 3(\mathrm{H} 2 \mathrm{O})$ in the alternative pathway. Front Immunol 11. https:// doi.org/10.3389/fimmu.2020.00530

12. Klos A, Tenner AJ, Johswich K-O et al (2009) The role of the anaphylatoxins in health and disease. Mol Immunol 46:27532766. https://doi.org/10.1016/j.molimm.2009.04.027

13. Coulthard LG, Woodruff TM (2015) Is the complement activation product $\mathrm{C} 3 \mathrm{a}$ a proinflammatory molecule? Re-evaluating the evidence and the myth. J Immunol 194:3542-3548. https://doi.org/ 10.4049/jimmunol.1403068

14. Lackner I, Weber B, Baur M et al (2020) Complement activation and organ damage after trauma - differential immune response based on surgical treatment strategy. Front Immunol:11. https:// doi.org/10.3389/fimmu.2020.00064

15. Vogt W, Schmidt G, Von Buttlar B, Dieminger L (1978) A new function of the activated third component of complement: binding to C5, an essential step for C5 activation. Immunology 34:29-40

16. Jore MM, Johnson S, Sheppard D et al (2016) Structural basis for therapeutic inhibition of complement C5. Nat Struct Mol Biol 23: 378-386. https://doi.org/10.1038/nsmb.3196

17. Mannes M, Dopler A, Zolk O et al (2021) Complement inhibition at the level of $\mathrm{C} 3$ or $\mathrm{C} 5$ : mechanistic reasons for ongoing terminal pathway activity. Blood 137:443-455. https://doi.org/10.1182/ blood.2020005959

18. DeLisi C, Boyle M (1950) Borsos T (1980) Analysis of the colloid osmotic step of complement-mediated immune hemolysis. J Immunol Baltim Md 125:2055-2062

19. Podack ER, Preissner KT, Müller-Eberhard HJ (1984) Inhibition of C9 polymerization within the SC5b-9 complex of complement by S-protein. Acta Pathol Microbiol Immunol Scand Suppl 284:89-96

20. Zhang $\mathrm{T}, \mathrm{Wu} \mathrm{K}, \mathrm{Ma} \mathrm{N}$ et al (2020) The $\mathrm{C} 5 \mathrm{a} / \mathrm{C} 5 \mathrm{aR} 2$ axis promotes renal inflammation and tissue damage. JCI Insight 5. https://doi. org/10.1172/jci.insight. 134081

21. Gerard NP, Lu B, Liu P et al (2005) An anti-inflammatory function for the complement anaphylatoxin C5a-binding protein, C5L2 *. J Biol Chem 280:39677-39680. https://doi.org/10. 1074/jbc.C500287200

22. Li CKN (1975) Proof of the one-hit mechanism of complementinduced lysis. Immunochemistry 12:89-92. https://doi.org/10. 1016/0019-2791(75)90054-3

23. Pilzer D, Gasser O, Moskovich O et al (2005) Emission of membrane vesicles: roles in complement resistance, immunity and cancer. Springer Semin Immunopathol 27:375-387. https://doi.org/ 10.1007/s00281-005-0004-1

24. Huber-Lang MS, Ignatius A, Köhl J et al (2020) Complement in trauma-traumatised complement? Br J Pharmacol. https://doi.org/ 10.1111/bph. 15245

25. Kilgore KS, Flory CM, Miller BF et al (1996) The membrane attack complex of complement induces interleukin- 8 and monocyte chemoattractant protein-1 secretion from human umbilical vein endothelial cells. Am J Pathol 149:953-961

26. Kilgore KS, Schmid E, Shanley TP et al (1997) Sublytic concentrations of the membrane attack complex of complement induce endothelial interleukin- 8 and monocyte chemoattractant protein-1 through nuclear factor-kappa B activation. Am J Pathol 150:2019-2031

27. Budding K, van de Graaf EA, Kardol-Hoefnagel T et al (2016) Soluble CD59 is a novel biomarker for the prediction of obstructive chronic lung allograft dysfunction after lung transplantation. Sci Rep 6:26274. https://doi.org/10.1038/srep26274

28. Lublin DM, Atkinson JP (1989) Decay-accelerating factor: biochemistry, molecular biology, and function. Annu Rev Immunol 7:35-58. https://doi.org/10.1146/annurev.iy.07.040189.000343

29. Schmidt CQ, Kennedy AT, Tham W-H (2015) More than just immune evasion: hijacking complement by Plasmodium falciparum. Mol Immunol 67:71-84. https://doi.org/10.1016/j. molimm.2015.03.006

30. Harris CL, Pettigrew DM, Lea SM, Morgan BP (2007) Decayaccelerating factor must bind both components of the complement alternative pathway $\mathrm{C} 3$ convertase to mediate efficient decay. J Immunol 178:352-359. https://doi.org/10.4049/jimmunol.178.1.352

31. Dalle Lucca JJ, Li Y, Simovic MO et al (2013) Decay-accelerating factor limits hemorrhage-instigated tissue injury and improves resuscitation clinical parameters. J Surg Res 179:153-167. https:// doi.org/10.1016/j.jss.2012.10.017

32. Li Y, Yang Z, Chavko M et al (2018) Complement inhibition ameliorates blast-induced acute lung injury in rats: potential role of complement in intracellular HMGB1-mediated inflammation. PLoS One 13:e202594. https://doi.org/10.1371/journal.pone.0202594

33. Ramaglia V, Wolterman R, de Kok M et al (2008) Soluble complement receptor 1 protects the peripheral nerve from early axon loss after injury. Am J Pathol 172:1043-1052. https://doi.org/10. 2353/ajpath.2008.070660

34. Liszewski MK, Post TW, Atkinson JP (1991) Membrane cofactor protein (MCP or CD46): newest member of the regulators of complement activation gene cluster. Annu Rev Immunol 9:431-455. https://doi.org/10.1146/annurev.iy.09.040191.002243

35. Amara U, Kalbitz M, Perl M et al (2010) Early expression changes of complement regulatory proteins and $\mathrm{C} 5 \mathrm{~A}$ receptor $(\mathrm{CD} 88)$ on leukocytes after multiple injury in humans. Shock Augusta Ga 33: 568-575. https://doi.org/10.1097/SHK.0b013e3181c799d4

36. Wang X, Zhang D, Sjölinder M et al (2017) CD46 accelerates macrophage-mediated host susceptibility to meningococcal sepsis in a murine model. Eur J Immunol 47:119-130. https://doi.org/10. 1002/eji.201646397

37. Cattaneo R (2004) Four viruses, two bacteria, and one receptor: membrane cofactor protein (CD46) as pathogens' magnet. J Virol 78:4385-4388. https://doi.org/10.1128/JVI.78.9.4385-4388.2004

38. Okada N, Liszewski MK, Atkinson JP, Caparon M (1995) Membrane cofactor protein (CD46) is a keratinocyte receptor for the M protein of the group A streptococcus. Proc Natl Acad Sci U S A 92:2489-2493

39. Fujita T, Gigli I, Nussenzweig V (1978) Human C4-binding protein. II. Role in proteolysis of C4b by C3b-inactivator. J Exp Med 148:1044-1051. https://doi.org/10.1084/jem.148.4.1044

40. Gigli I, Fujita T, Nussenzweig V (1979) Modulation of the classical pathway $\mathrm{C} 3$ convertase by plasma proteins $\mathrm{C} 4$ binding protein and C3b inactivator. Proc Natl Acad Sci U S A 76:6596-6600

41. Rezende SM, Simmonds RE, Lane DA (2004) Coagulation, inflammation, and apoptosis: different roles for protein $\mathrm{S}$ and the protein S-C4b binding protein complex. Blood 103:1192-1201. https://doi.org/10.1182/blood-2003-05-1551

42. Albert-Weissenberger C, Mencl S, Schuhmann MK et al (2014) C1-Inhibitor protects from focal brain trauma in a cortical cryolesion mice model by reducing thrombo-inflammation. Front Cell Neurosci 8:269. https://doi.org/10.3389/fncel.2014.00269 
43. Liu D, Lu F, Qin G et al (2007) C1 Inhibitor-mediated protection from sepsis. J Immunol 179:3966-3972. https://doi.org/10.4049/ jimmunol.179.6.3966

44. Dopler A, Guntau L, Harder MJ et al (2019) Self versus nonself discrimination by the soluble complement regulators factor $\mathrm{H}$ and FHL-1. J Immunol. https://doi.org/10.4049/jimmunol.1801545

45. Mannes M, Dopler A, Huber-Lang M, Schmidt CQ (2020) Tuning the functionality by splicing: factor $\mathrm{H}$ and its alternative splice variant FHL-1 share a gene but not all functions. Front Immunol 11. https://doi.org/10.3389/fimmu.2020.596415

46. Cserhalmi M, Papp A, Brandus B et al (2019) Regulation of regulators: role of the complement factor H-related proteins. Semin Immunol 45:101341. https://doi.org/10.1016/j.smim.2019.101341

47. Józsi M (2017) Factor $H$ family proteins in complement evasion of microorganisms. Front Immunol 8:571. https://doi.org/10.3389/ fimmu.2017.00571

48. Kárpáti É, Papp A, Schneider AE et al (2020) Interaction of the factor $\mathrm{H}$ family proteins FHR-1 and FHR-5 with DNA and dead cells: implications for the regulation of complement activation and opsonization. Front Immunol 11. https://doi.org/10.3389/fimmu. 2020.01297

49. Jain S, Gautam V, Naseem S (2011) Acute-phase proteins: as diagnostic tool. J Pharm Bioallied Sci 3:118-127. https://doi.org/ 10.4103/0975-7406.76489

50. Liao W, Li Y, Chen T et al (2004) Determination of serum acute phase reaction protein in patients with severe acute respiratory syndrome. Zhonghua Yu Fang Yi Xue Za Zhi 38:92-93

51. Sharma B, Gupta B, Sharma DK, Talib VH (2013) Study of Creactive protein and $\mathrm{C} 3$ complement as acute phase reactants in unstable angina. J Indian Med Assoc 111:388-390

52. Szalai AJ, van Ginkel FW, Wang Y et al (2000) Complementdependent acute-phase expression of $\mathrm{C}$-reactive protein and serum amyloid P-component. J Immunol 165:1030-1035. https://doi. org/10.4049/jimmunol.165.2.1030

53. Dzik S (2019) Complement and coagulation: cross talk through time. Transfus Med Rev 33:199-206. https://doi.org/10.1016/j. tmrv.2019.08.004

54. Wiegner R, Chakraborty S, Huber-Lang M (2016) Complementcoagulation crosstalk on cellular and artificial surfaces. Immunobiology 221:1073-1079. https://doi.org/10.1016/j.imbio. 2016.06.005

55. Markiewski MM, Nilsson B, Ekdahl KN et al (2007) Complement and coagulation: strangers or partners in crime? Trends Immunol 28:184-192. https://doi.org/10.1016/j.it.2007.02.006

56. Krisinger MJ, Goebeler V, Lu Z et al (2012) Thrombin generates previously unidentified $\mathrm{C} 5$ products that support the terminal complement activation pathway. Blood 120:1717-1725. https:// doi.org/10.1182/blood-2012-02-412080

57. Amara U, Flierl MA, Rittirsch D et al (1950) (2010) Molecular intercommunication between the complement and coagulation systems. J Immunol Baltim Md 185:5628-5636. https://doi.org/ 10.4049/jimmunol.0903678

58. Huber-Lang M, Ekdahl KN, Wiegner R et al (2018) Auxiliary activation of the complement system and its importance for the pathophysiology of clinical conditions. Semin Immunopathol 40: 87-102. https://doi.org/10.1007/s00281-017-0646-9

59. Krarup A, Wallis R, Presanis JS et al (2007) Simultaneous activation of complement and coagulation by MBL-associated serine protease 2 . PLoS One 2:e623. https://doi.org/10.1371/journal.pone.0000623

60. Krarup A, Gulla KC, Gál P et al (2008) The action of MBLassociated serine protease 1 (MASP1) on factor XIII and fibrinogen. Biochim Biophys Acta 1784:1294-1300. https://doi.org/10. 1016/j.bbapap.2008.03.020

61. Ekdahl KN, Fromell K, Mohlin C et al (2019) A human wholeblood model to study the activation of innate immunity system triggered by nanoparticles as a demonstrator for toxicity. Sci
Technol Adv Mater 20:688-698. https://doi.org/10.1080/ 14686996.2019.1625721

62. Sokolov A, Hellerud BC, Tønnessen TI et al (2013) Activation of coagulation and platelets by candidate membranes of implantable devices in a whole blood model without soluble anticoagulant. J Biomed Mater Res A 101A:575-581. https://doi.org/10.1002/ jbm.a. 34348

63. Sottrup-Jensen L, Stepanik TM, Kristensen T et al (1985) Common evolutionary origin of alpha 2-macroglobulin and complement components C3 and C4. Proc Natl Acad Sci U S A 82:9-13

64. Najafpour B, Cardoso JCR, Canário AVM, Power DM (2020) Specific evolution and gene family expansion of complement 3 and regulatory factor $\mathrm{H}$ in fish. Front Immunol 11:568631. https:// doi.org/10.3389/fimmu.2020.568631

65. Rodriguez de Cordoba S, Lublin DM, Rubinstein P, Atkinson JP (1985) Human genes for three complement components that regulate the activation of C3 are tightly linked. J Exp Med 161:1189 1195. https://doi.org/10.1084/jem.161.5.1189

66. Ekdahl KN, Teramura Y, Hamad OA et al (2016) Dangerous liaisons: complement, coagulation, and kallikrein/kinin cross-talk act as a linchpin in the events leading to thromboinflammation. Immunol Rev 274:245-269. https://doi.org/10.1111/imr.12471

67. Huber-Lang M, Lambris JD, Ward PA (2018) Innate immune responses to trauma. Nat Immunol 19:327-341. https://doi.org/ 10.1038/s41590-018-0064-8

68. Messerer DAC, Halbgebauer R, Nilsson B et al (2020) Immunopathophysiology of trauma-related acute kidney injury. Nat Rev Nephrol. https://doi.org/10.1038/s41581-020-00344-9

69. Hecke F, Schmidt U, Kola A et al (1997) Circulating complement proteins in multiple trauma patients-correlation with injury severity, development of sepsis, and outcome. Crit Care Med 25:20152024. https://doi.org/10.1097/00003246-199712000-00019

70. Ganter MT, Brohi K, Cohen MJ et al (2007) Role of the alternative pathway in the early complement activation following major trauma. Shock Augusta Ga 28:29-34. https://doi.org/10.1097/shk. 0b013e3180342439

71. Burk A-M, Martin M, Flierl MA et al (2012) Early complementopathy after multiple injuries in humans. Shock Augusta Ga 37:348-354. https://doi.org/10.1097/SHK. 0b013e3182471795

72. Li Y, Zhao Q, Liu B et al (2019) Early complementopathy predicts the outcomes of patients with trauma. Trauma Surg Acute Care Open 4:e000217. https://doi.org/10.1136/tsaco-2018-000217

73. Kellermann W, Frentzel-Beyme R, Welte M, Jochum M (1989) Phospholipase A in acute lung injury after trauma and sepsis: its relation to the inflammatory mediators PMN-elastase, C3a, and neopterin. Klin Wochenschr 67:190-195. https://doi.org/10. 1007/BF01711352

74. Denk S, Neher MD, Messerer DAC et al (2017) Complement C5a functions as a master switch for the $\mathrm{pH}$ balance in neutrophils exerting fundamental immunometabolic effects. J Immunol. https://doi.org/10.4049/jimmunol.1700393

75. Morris AC, Brittan M, Wilkinson TS et al (2011) C5a-mediated neutrophil dysfunction is RhoA-dependent and predicts infection in critically ill patients. Blood 117:5178-5188. https://doi.org/10. 1182/blood-2010-08-304667

76. Kanse SM, Gallenmueller A, Zeerleder S et al (1950) (2012) Factor VII-activating protease is activated in multiple trauma patients and generates anaphylatoxin C5a. J Immunol Baltim Md 188:2858-2865. https://doi.org/10.4049/jimmunol.1103029

77. Huber-Lang M, Denk S, Fulda S et al (2012) Cathepsin D is released after severe tissue trauma in vivo and is capable of generating C5a in vitro. Mol Immunol 50:60-65. https://doi.org/10. 1016/j.molimm.2011.12.005 
78. Perl M, Denk S, Kalbitz M, Huber-Lang M (2012) Granzyme B: a new crossroad of complement and apoptosis. Adv Exp Med Biol 946:135-146. https://doi.org/10.1007/978-1-4614-0106-3_8

79. Keshari RS, Silasi R, Lupu C et al (2017) In vivo-generated thrombin and plasmin do not activate the complement system in baboons. Blood 130:2678-2681. https://doi.org/10.1182/blood2017-06-788216

80. Banerjee A, Silliman CC, Moore EE et al (2018) Systemic hyperfibrinolysis after trauma: a pilot study of targeted proteomic analysis of superposed mechanisms in patient plasma. J Trauma Acute Care Surg 84:929-938. https://doi.org/10.1097/TA. 0000000000001878

81. Karasu E, Demmelmaier J, Kellermann S et al (2020) Complement C5a induces pro-inflammatory microvesicle shedding in severely injured patients. Front Immunol 11. https://doi. org/10.3389/fimmu.2020.01789

82. Taylor R (2007) Fresh frozen plasma as a complement source. Lancet Oncol 8:370-371. https://doi.org/10.1016/S14702045(07)70114-6

83. Chen J, Losos M, Yang S et al (2017) Increased complement activation during platelet storage. Transfusion (Paris) 57:21822188. https://doi.org/10.1111/trf.14215

84. Barrett CD, Vigneshwar N, Moore HB et al (2020) Tranexamic acid is associated with reduced complement activation in trauma patients with hemorrhagic shock and hyperfibrinolysis on thromboelastography. Blood Coagul Fibrinolysis Int J Haemost Thromb 31:578-582. https://doi.org/10.1097/MBC.0000000000000938

85. Gleason TG, Argenziano M, Bavaria JE et al (2019) Hemoadsorption to reduce plasma-free hemoglobin during cardiac surgery: results of REFRESH I pilot study. Semin Thorac Cardiovasc Surg 31:783-793. https://doi.org/10.1053/j.semtcvs.2019.05.006

86. Heeres M, Visser T, van Wessem KJP et al (2011) The effect of $\mathrm{C} 1$-esterase inhibitor on systemic inflammation in trauma patients with a femur fracture - the CAESAR study: study protocol for a randomized controlled trial. Trials 12:223. https://doi.org/10. 1186/1745-6215-12-223

87. van Griensven M, Ricklin D, Denk S et al (2019) Protective effects of the complement inhibitor compstatin CP40 in hemorrhagic shock. Shock Augusta Ga 51:78-87. https://doi.org/10.1097/ SHK.0000000000001127

88. Paredes RM, Reyna S, Vernon P et al (2018) Generation of complement molecular complex C5b-9 (C5b-9) in response to polytraumatic hemorrhagic shock and evaluation of C5 cleavage inhibitors in non-human primates. Int Immunopharmacol 54:221225. https://doi.org/10.1016/j.intimp.2017.10.033

89. Jain M, Duggal S, Chugh TD (2011) Cytomegalovirus infection in non-immunosuppressed critically ill patients. J Infect Dev Ctries 5:571-579. https://doi.org/10.3855/jidc. 1487

90. Greenhalgh DG (2019) Management of burns. N Engl J Med. https://doi.org/10.1056/NEJMra1807442

91. Breetveld M, Richters CD, Rustemeyer T et al (2006) Comparison of wound closure after burn and cold injury in human skin equivalents. J Invest Dermatol 126:1918-1921. https://doi.org/10.1038/ sj.jid.5700330

92. Papini R (2004) Management of burn injuries of various depths. BMJ 329:158-160. https://doi.org/10.1136/bmj.329.7458.158

93. Jeschke MG, Mlcak RP, Finnerty CC et al (2007) Burn size determines the inflammatory and hypermetabolic response. Crit Care Lond Engl 11:R90. https://doi.org/10.1186/cc6102

94. Sriramarao P, DiScipio RG (1999) Deposition of complement C3 and factor $\mathrm{H}$ in tissue traumatized by burn injury. Immunopharmacology 42:195-202. https://doi.org/10.1016/ s0162-3109(99)00024-7

95. Friedl HP, Till GO, Trentz O, Ward PA (1989) Roles of histamine, complement and xanthine oxidase in thermal injury of skin. Am J Pathol 135:203-217
96. Hatherill JR, Till GO, Bruner LH, Ward PA (1986) Thermal injury, intravascular hemolysis, and toxic oxygen products. J Clin Invest 78:629-636. https://doi.org/10.1172/JCI112620

97. Till GO, Beauchamp C, Menapace D et al (1983) Oxygen radical dependent lung damage following thermal injury of rat skin. $\mathrm{J}$ Trauma 23:269-277. https://doi.org/10.1097/00005373198304000-00001

98. Ward PA, Till GO (1990) Pathophysiologic events related to thermal injury of skin. J Trauma 30:S75-S79. https://doi.org/10.1097/ 00005373-199012001-00018

99. Gelfand JA, Donelan M, Hawiger A, Burke JF (1982) Alternative complement pathway activation increases mortality in a model of burn injury in mice. J Clin Invest 70:1170-1176. https://doi.org/ 10.1172/jci1 10715

100. Modi S, Rashid M, Malik A, Shahid M (2014) Study of complement activation, $\mathrm{C} 3$ and interleukin- 6 levels in burn patients and their role as prognostic markers. Indian J Med Microbiol 32:137. https://doi.org/10.4103/0255-0857.129793

101. Kang HJ, Kim JH, Lee EH et al (2003) Change of complement system predicts the outcome of patients with severe thermal injury. J Burn Care Rehabil 24:148-153. https://doi.org/10.1097/01. BCR.0000066791.85810.BC

102. Solomkin JS, Nelson RD, Chenoweth DE et al (1984) Regulation of neutrophil migratory function in burn injury by complement activation products. Ann Surg 200:742-746. https://doi.org/10. 1097/00000658-198412000-00012

103. Moran KT, O’Reilly TJ, Allo M, Munster AM (1987) Anaphylotoxin levels following thermal injury. Burns Incl Therm Inj 13:266-268. https://doi.org/10.1016/0305-4179(87)90043-x

104. Wan KC, Lewis WH, Leung PC et al (1998) A longitudinal study of C3, C3d and factor Ba in burn patients in Hong Kong Chinese. Burns J Int Soc Burn Inj 24:241-244. https://doi.org/10.1016/ s0305-4179(98)00013-8

105. Korkmaz HI, Krijnen PAJ, Ulrich MMW et al (2017) The role of complement in the acute phase response after burns. Burns J Int Soc Burn Inj 43:1390-1399. https://doi.org/10.1016/j.burns.2017.03.007

106. Henze U, Lennartz A, Hafemann B et al (1997) The influence of the $\mathrm{C} 1$-inhibitor BERINERT and the protein-free haemodialysate ACTIHAEMYL20\% on the evolution of the depth of scald burns in a porcine model. Burns J Int Soc Burn Inj 23:473-477. https:// doi.org/10.1016/s0305-4179(97)00019-3

107. Khorram-Sefat R, Goldmann C, Radke A et al (1998) The therapeutic effect of $\mathrm{C} 1$-inhibitor on gut-derived bacterial translocation after thermal injury. Shock Augusta Ga 9:101-108. https://doi. org/10.1097/00024382-199802000-00005

108. Radke A, Mottaghy K, Goldmann C et al (2000) C1 inhibitor prevents capillary leakage after thermal trauma. Crit Care Med 28: 3224-3232. https://doi.org/10.1097/00003246-200009000-00018

109. Korkmaz HI, Ulrich MMW, Wieringen WNV et al (2020) C1 inhibitor administration reduces local inflammation and capillary leakage, without affecting long-term wound healing parameters, in a pig burn wound model. Anti-Inflamm Anti-Allergy Agents Med Chem. https://doi.org/10.2174/1871523019666200702101513

110. Begieneman MPV, Kubat B, Ulrich MMW et al (2012) Prolonged C1 inhibitor administration improves local healing of burn wounds and reduces myocardial inflammation in a rat burn wound model. J Burn Care Res Off Publ Am Burn Assoc 33:544-551. https://doi.org/10.1097/BCR.0b013e31823bc2fc

111. Williams FN, Herndon DN, Suman OE et al (2011) Changes in cardiac physiology after severe burn injury. J Burn Care Res Off Publ Am Burn Assoc 32:269-274. https://doi.org/10.1097/BCR. 0b013e31820aafcf

112. Niederbichler AD, Hoesel LM, Westfall MV et al (2006) An essential role for complement $\mathrm{C} 5 \mathrm{a}$ in the pathogenesis of septic cardiac dysfunction. J Exp Med 203:53-61. https://doi.org/10. 1084/jem.20051207 
113. Hoesel LM, Niederbichler AD, Schaefer J et al (1950) (2007) C5ablockade improves burn-induced cardiac dysfunction. J Immunol Baltim Md 178:7902-7910. https://doi.org/10.4049/jimmunol. 178.12.7902

114. Schmid E, Piccolo MT, Friedl HP et al (1997) Requirement for C5a in lung vascular injury following thermal trauma to rat skin. Shock Augusta Ga 8:119-124. https://doi.org/10.1097/00024382199708000-00010

115. Suber F, Carroll MC, Moore FD (2007) Innate response to selfantigen significantly exacerbates burn wound depth. Proc Natl Acad Sci U S A 104:3973-3977. https://doi.org/10.1073/pnas. 0609026104

116. Bone RC, Balk RA, Cerra FB et al (1992) Definitions for sepsis and organ failure and guidelines for the use of innovative therapies in sepsis. The ACCP/SCCM Consensus Conference Committee. American College of Chest Physicians/Society of Critical Care Medicine. Chest 101:1644-1655. https://doi.org/10.1378/chest. 101.6.1644

117. Singer M, Deutschman CS, Seymour CW et al (2016) The third international consensus definitions for sepsis and septic shock (sepsis-3). JAMA 315:801-810. https://doi.org/10.1001/jama. 2016.0287

118. Czermak BJ, Sarma V, Pierson CL et al (1999) Protective effects of C5a blockade in sepsis. Nat Med 5:788-792. https://doi.org/10. $1038 / 10512$

119. Ward PA (2004) The dark side of C5a in sepsis. Nat Rev Immunol 4:133-142. https://doi.org/10.1038/nri1269

120. Stöve S, Welte T, Wagner TO et al (1996) Circulating complement proteins in patients with sepsis or systemic inflammatory response syndrome. Clin Diagn Lab Immunol 3:175-183

121. Unnewehr H, Rittirsch D, Sarma JV et al (2013) Changes and regulation of the $\mathrm{C} 5$ a receptor on neutrophils during septic shock in humans. J Immunol 190:4215-4225. https://doi.org/10.4049/ jimmunol.1200534

122. Rittirsch D, Flierl MA, Nadeau BA et al (2008) Functional roles for C5a receptors in sepsis. Nat Med 14:551-557. https://doi.org/ $10.1038 / \mathrm{nm} 1753$

123. Huber-Lang M, Sarma JV, Rittirsch D et al (2005) Changes in the novel orphan, C5a receptor (C5L2), during experimental sepsis and sepsis in humans. J Immunol 174:1104-1110. https://doi. org/10.4049/jimmunol.174.2.1104

124. Ritis K, Doumas M, Mastellos D et al (1950) (2006) A novel C5a receptor-tissue factor cross-talk in neutrophils links innate immunity to coagulation pathways. J Immunol Baltim Md 177:4794 4802. https://doi.org/10.4049/jimmunol.177.7.4794

125. Fusakio ME, Mohammed JP, Laumonnier Y et al (1950) (2011) C5a regulates NKT and NK cell functions in sepsis. J Immunol Baltim Md 187:5805-5812. https://doi.org/10.4049/jimmunol.1100338

126. Nadeau S, Rivest $S$ (2001) The complement system is an integrated part of the natural innate immune response in the brain. FASEB J Off Publ Fed Am Soc Exp Biol 15:1410-1412. https://doi.org/ 10.1096/fj.00-0709fje

127. Rupprecht TA, Angele B, Klein M et al (2007) Complement C1q and $\mathrm{C} 3$ are critical for the innate immune response to Streptococcus pneumoniae in the central nervous system. J Immunol 178:18611869. https://doi.org/10.4049/jimmunol.178.3.1861

128. Lindsberg PJ, Ohman J, Lehto T et al (1996) Complement activation in the central nervous system following blood-brain barrier damage in man. Ann Neurol 40:587-596. https://doi.org/10.1002/ ana.410400408

129. Jacob A, Hensley LK, Safratowich BD et al (2007) The role of the complement cascade in endotoxin-induced septic encephalopathy. Lab Investig J Tech Methods Pathol 87:1186-1194. https://doi. org/10.1038/labinvest.3700686

130. Huang P, Zhou Q, Lin Q et al (2020) Complement C3a induces axonal hypomyelination in the periventricular white matter through activation of $\mathrm{WNT} / \beta$-catenin signal pathway in septic neonatal rats experimentally induced by lipopolysaccharide. Brain Pathol 30:495-514. https://doi.org/10.1111/bpa.12798

131. Boos L, Szalai AJ, Barnum SR (2005) C3a expressed in the central nervous system protects against LPS-induced shock. Neurosci Lett 387:68-71. https://doi.org/10.1016/j.neulet.2005.07.015

132. van Beek J, Nicole O, Ali C et al (2001) Complement anaphylatoxin $\mathrm{C} 3 \mathrm{a}$ is selectively protective against NMDAinduced neuronal cell death. Neuroreport 12:289-293. https:// doi.org/10.1097/00001756-200102120-00022

133. Flierl MA, Stahel PF, Rittirsch D et al (2009) Inhibition of complement C5a prevents breakdown of the blood-brain barrier and pituitary dysfunction in experimental sepsis. Crit Care Lond Engl 13:R12. https://doi.org/10.1186/cc7710

134. Jacob A, Hack B, Chiang E et al (2010) C5a alters blood-brain barrier integrity in experimental lupus. FASEB J Off Publ Fed Am Soc Exp Biol 24:1682-1688. https://doi.org/10.1096/fj.09-138834

135. Annane D (2009) Sepsis-associated delirium: the pro and con of C5a blockade. Crit Care 13:135. https://doi.org/10.1186/cc7754

136. Orhun G, Esen F, Özcan PE et al (2019) Neuroimaging findings in sepsis-induced brain dysfunction: association with clinical and laboratory findings. Neurocrit Care 30:106-117. https://doi.org/ 10.1007/s12028-018-0581-1

137. Esen F, Orhun G, Ozcan PE et al (2017) Neuroprotective effects of intravenous immunoglobulin are mediated through inhibition of complement activation and apoptosis in a rat model of sepsis. Intensive Care Med Exp:5. https://oi.org/10.1186/s40635-016-0114-1

138. Zhang Z, Yan C, Miao J et al (2020) Muscle-derived mitochondrial transplantation reduces inflammation, enhances bacterial clearance, and improves survival in sepsis. Shock Augusta Ga. https://doi.org/10.1097/SHK.0000000000001681

139. Busund R, Balteskard L, Rønning G et al (1995) Fatal myocardial depression and circulatory collapse associated with complement activation induced by plasma infusion in severe porcine sepsis. Acta Anaesthesiol Scand 39:100-108. https://doi.org/10.1111/j. 1399-6576.1995.tb05600.x

140. Dorresteijn MJ, Visser T, Cox LAE et al (2010) C1-esterase inhibitor attenuates the inflammatory response during human endotoxemia. Crit Care Med 38:2139-2145. https://doi.org/10. 1097/CCM.0b013e3181f17be4

141. Quezado ZM, Hoffman WD, Winkelstein JA et al (1994) The third component of complement protects against Escherichia coli endotoxin-induced shock and multiple organ failure. J Exp Med 179:569-578. https://doi.org/10.1084/jem.179.2.569

142. Silasi-Mansat R, Zhu H, Popescu NI et al (2010) Complement inhibition decreases the procoagulant response and confers organ protection in a baboon model of Escherichia coli sepsis. Blood 116:1002-1010. https://doi.org/10.1182/blood-2010-02-269746

143. Keshari RS, Silasi R, Popescu NI et al (2017) Inhibition of complement $\mathrm{C} 5$ protects against organ failure and reduces mortality in a baboon model of Escherichia coli sepsis. Proc Natl Acad Sci 114:E6390-E6399. https://doi.org/10.1073/pnas.1706818114

144. Riedemann NC, Neff TA, Guo R-F et al (1950) (2003) Protective effects of IL-6 blockade in sepsis are linked to reduced C5a receptor expression. J Immunol Baltim Md 170:503-507. https://doi. org/10.4049/jimmunol.170.1.503

145. Gao H, Neff TA, Guo R-F et al (2005) Evidence for a functional role of the second C5a receptor C5L2. FASEB J 19:1003-1005. https://doi.org/10.1096/fj.04-3424fje

146. Kalbitz M, Fattahi F, Herron TJ et al (1950) (2016) Complement destabilizes cardiomyocyte function in vivo after polymicrobial sepsis and in vitro. J Immunol Baltim Md 197:2353-2361. https://doi.org/10.4049/jimmunol.1600091

147. Fattahi F, Kalbitz M, Malan EA et al (2017) Complement-induced activation of MAPKs and Akt during sepsis: role in cardiac 
dysfunction. FASEB J Off Publ Fed Am Soc Exp Biol 31:41294139. https://doi.org/10.1096/fj.201700140R

148. Kalbitz M, Fattahi F, Grailer JJ et al (2016) Complement-induced activation of the cardiac NLRP3 inflammasome in sepsis. FASEB J Off Publ Fed Am Soc Exp Biol 30:3997-4006. https://doi.org/ 10.1096/fj.201600728R

149. Kalbitz M, Grailer JJ, Fattahi F et al (2015) Role of extracellular histones in the cardiomyopathy of sepsis. FASEB J 29:21852193. https://doi.org/10.1096/fj.14-268730

150. Atefi G, Zetoune FS, Herron TJ et al (2011) Complement dependency of cardiomyocyte release of mediators during sepsis. FASEB J 25:2500-2508. https://doi.org/10.1096/fj.11-183236

151. Keshari RS, Silasi R, Popescu NI et al (2020) CD14 inhibition improves survival and attenuates thrombo-inflammation and cardiopulmonary dysfunction in a baboon model of Escherichia coli sepsis. J Thromb Haemost JTH. https://doi.org/10.1111/jth.15162

152. Zou L, Feng Y, Li Y et al (1950) (2013) Complement factor B is the downstream effector of TLRs and plays an important role in a mouse model of severe sepsis. J Immunol Baltim Md 191:56255635. https://doi.org/10.4049/jimmunol.1301903

153. Egge KH, Thorgersen EB, Pischke SE et al (2015) Organ inflammation in porcine Escherichia coli sepsis is markedly attenuated by combined inhibition of C5 and CD14. Immunobiology 220: 999-1005. https://doi.org/10.1016/j.imbio.2015.04.002

154. Khor KH, Moore TA, Shiels IA et al (2016) A potential link between the C5a receptor 1 and the $\beta 1$-adrenoreceptor in the mouse heart. PLoS One 11:e0146022. https://doi.org/10.1371/ journal.pone.0146022

155. Koch T, Annuss C, Schiefer HG et al (1997) Impaired bacterial clearance after activation of the complement and coagulation systems. Shock Augusta Ga 7:42-48. https://doi.org/10.1097/ 00024382-199701000-00005

156. Giebler R, Schmidt U, Koch S et al (1999) Combined antithrombin III and C1-esterase inhibitor treatment decreases intravascular fibrin deposition and attenuates cardiorespiratory impairment in rabbits exposed to Escherichia coli endotoxin. Crit Care Med 27: 597-604. https://doi.org/10.1097/00003246-199903000-00042

157. Risitano AM, Mastellos DC, Huber-Lang M et al (2020) Complement as a target in COVID-19? Nat Rev Immunol 20: 343-344. https://doi.org/10.1038/s41577-020-0320-7

158. Mastaglio S, Ruggeri A, Risitano AM et al (2020) The first case of COVID-19 treated with the complement C3 inhibitor AMY-101. Clin Immunol Orlando Fla 215:108450. https://doi.org/10.1016/j. clim.2020.108450

159. Polycarpou A, Howard M, Farrar CA et al (2020) Rationale for targeting complement in COVID-19. EMBO Mol Med 12: e12642. https://doi.org/10.15252/emmm.202012642

160. Bergh K, Olsen PO, Halgunset J, Iversen OJ (1991) Complement activation and pulmonary dysfunction in experimental Escherichia coli septicaemia. Acta Anaesthesiol Scand 35:267-274. https:// doi.org/10.1111/j.1399-6576.1991.tb03286.x

161. Dehring DJ, Steinberg SM, Martin DT et al (1984) Effects of complement depletion on pulmonary dysfunction in porcine septic acute respiratory failure. Curr Surg 41:195-197

162. Guerrero R, Velasco F, Rodriguez M et al (1993) Endotoxin-induced pulmonary dysfunction is prevented by $\mathrm{C} 1$-esterase inhibitor. J Clin Invest 91:2754-2760. https://doi.org/10.1172/JCI116516

163. Müller-Redetzky H, Kellermann U, Wienhold S-M et al (2020) Neutralizing complement C5a protects mice with pneumococcal pulmonary sepsis. Anesthesiology 132:795-807. https://doi.org/ 10.1097/ALN.0000000000003149

164. Huber-Lang MS, Sarma JV, McGuire SR et al (2001) Protective effects of anti-C5a peptide antibodies in experimental sepsis. FASEB J 15:568-570. https://doi.org/10.1096/fj.00-0653fje
165. Olson LM, Moss GS, Baukus O, Das Gupta TK (1985) The role of C5 in septic lung injury. Ann Surg 202:771-776. https://doi.org/ 10.1097/00000658-198512000-00018

166. Buras JA, Rice L, Orlow D et al (2004) Inhibition of C5 or absence of C6 protects from sepsis mortality. Immunobiology 209:629 635. https://doi.org/10.1016/j.imbio.2004.09.004

167. Fattahi F, Grailer JJ, Parlett M et al (2020) Requirement of complement C6 for intact innate immune responses in mice. J Immunol. https://doi.org/10.4049/jimmunol.1900801

168. Yuan Y, Ren J, Gu G et al (2012) The effect of human complement $\mathrm{C} 3$ protein applied at different times in treatment of polymicrobial sepsis. Inflamm Res Off J Eur Histamine Res Soc Al 61:581-589. https://doi.org/10.1007/s00011-012-0448-4

169. Flierl MA, Rittirsch D, Nadeau BA et al (2008) Functions of the complement components $\mathrm{C} 3$ and $\mathrm{C} 5$ during sepsis. FASEB J 22: 3483-3490. https://doi.org/10.1096/fj.08-110595

170. Bosmann M, Ward PA (2012) Role of C3, C5 and anaphylatoxin receptors in acute lung injury and in sepsis. Adv Exp Med Biol 946:147-159. https://doi.org/10.1007/978-1-4614-0106-3 9

171. Weinberg PF, Matthay MA, Webster RO et al (1984) Biologically active products of complement and acute lung injury in patients with the sepsis syndrome. Am Rev Respir Dis 130:791-796. https://doi.org/10.1164/arrd.1984.130.5.791

172. Hammerschmidt DE, Weaver LJ, Hudson LD et al (1980) Association of complement activation and elevated plasma-C5a with adult respiratory distress syndrome. Pathophysiological relevance and possible prognostic value. Lancet Lond Engl 1:947949. https://doi.org/10.1016/s0140-6736(80)91403-8

173. Tennenberg SD, Jacobs MP, Solomkin JS (1960) (1987) Complement-mediated neutrophil activation in sepsis- and trauma-related adult respiratory distress syndrome. Clarification with radioaerosol lung scans. Arch Surg Chic Ill 122:26-32. https://doi.org/10.1001/archsurg.1987.01400130032004

174. Eiseman B, Sloan R, Hansbrough J, McIntosh R (1980) Multiple organ failure: clinical and experimental. Am Surg 46:14-19

175. Langlois PF, Gawryl MS (1988) Accentuated formation of the terminal C5b-9 complement complex in patient plasma precedes development of the adult respiratory distress syndrome. Am Rev Respir Dis 138:368-375. https://doi.org/10.1164/ajrccm/138.2.368

176. Stevens JH, O'Hanley P, Shapiro JM et al (1986) Effects of antiC5a antibodies on the adult respiratory distress syndrome in septic primates. J Clin Invest 77:1812-1816. https://doi.org/10.1172/ JCI1 12506

177. Hangen DH, Stevens JH, Satoh PS et al (1989) Complement levels in septic primates treated with anti-C5a antibodies. J Surg Res 46: 195-199. https://doi.org/10.1016/0022-4804(89)90055-3

178. Hangen DH, Segall GM, Harney EW et al (1990) Kinetics of leukocyte sequestration in the lungs of acutely septic primates: a study using 111In-labeled autologous leukocytes. J Surg Res 48: 196-203. https://doi.org/10.1016/0022-4804(90)90213-1

179. Silasi-Mansat R, Zhu H, Georgescu C et al (2015) Complement inhibition decreases early fibrogenic events in the lung of septic baboons. J Cell Mol Med 19:2549-2563. https://doi.org/10.1111/ jcmm. 12667

180. Fronhoffs S, Luyken J, Steuer K et al (2000) The effect of C1esterase inhibitor in definite and suspected streptococcal toxic shock syndrome. Report of seven patients. Intensive Care Med 26:1566-1570. https://doi.org/10.1007/s001340000654

Publisher's note Springer Nature remains neutral with regard to jurisdictional claims in published maps and institutional affiliations. 